\title{
Pituitary Tumors: Genetic and Molecular Factors Underlying Pathogenesis and Clinical Behavior
}

\author{
Anna Spada a Giovanna Mantovani ${ }^{a, b}$ Andrea G. Lania ${ }^{c, d}$ \\ Donatella Treppiedi $^{a}$ Federica Mangili $^{\mathrm{a}}$ Rosa Catalano $^{\mathrm{a}}$ Giulia Carosi $^{\mathrm{b}}$ \\ Elisa Sala ${ }^{b}$ Erika Peverellia \\ ${ }^{a}$ Department of Clinical Sciences and Community Health, University of Milan, Milan, Italy; ${ }^{\text {b}}$ Endocrinology Unit, \\ Fondazione IRCCS Ca' Granda Ospedale Maggiore Policlinico, Milan, Italy; 'Endocrinology, Diabetology and Medical \\ Andrology Unit, Humanitas Clinical and Research Center, IRCCS, Milan, Italy; ${ }^{d}$ Department of Biomedical Sciences, \\ Humanitas University, Milan, Italy
}

\section{Keywords}

Pituitary tumors - Pathogenesis - Clinical behavior - Genetic alterations · Filamin A · Cofilin · Beta-arrestins

\begin{abstract}
Pituitary neuroendocrine tumors (PitNETs) are the most common intracranial neoplasms. Although generally benign, they can show a clinically aggressive course, with local invasion, recurrences, and resistance to medical treatment. No universally accepted biomarkers of aggressiveness are available yet, and predicting clinical behavior of PitNETs remains a challenge. In rare cases, the presence of germline mutations in specific genes predisposes to PitNET formation, as part of syndromic diseases or familial isolated pituitary adenomas, and associates to more aggressive, invasive, and drug-resistant tumors. The vast majority of cases is represented by sporadic PitNETs. Somatic mutations in the a subunit of the stimulatory $\mathrm{G}$ protein gene (gsp) and in the ubiquitin-specific protease 8 (USP8) gene have been recognized as pathogenetic factors in sporadic $\mathrm{GH}$ - and ACTH-secreting PitNETs, respectively, without an association with a worse clinical phenotype. Other molecular factors have been found to significantly affect PitNET drug responsiveness and inva-
\end{abstract}

sive behavior. These molecules are cytoskeleton and/or scaffold proteins whose alterations prevent proper functioning of the somatostatin and dopamine receptors, targets of medical therapy, or promote the ability of tumor cells to invade surrounding tissues. The aim of the present review is to provide an overview of the genetic and molecular alterations that can contribute to determine PitNET clinical behavior. Understanding subcellular mechanisms underlying pituitary tumorigenesis and PitNET clinical phenotype will hopefully lead to identification of new potential therapeutic targets and new markers predicting the behavior and the response to therapeutic treatments of PitNETs.

(c) 2021 S. Karger AG, Basel

\section{Introduction}

Pituitary tumors, more recently referred to as pituitary neuroendocrine tumors (PitNETs) [1, 2], are common neoplasms representing $\sim 10-20 \%$ of intracranial neo-

This article is based on the presentation for the 2020 ENEA Rolf Gaillard Prize Lecture at ENEA 2020 Meeting, 27 November 2020, Porto, Portugal.
Erika Peverelli

Department of Clinical Sciences and Community Health, University of Milan Via Pace, 9

IT-20122 Milan (Italy)

erika.peverelli@unimi.it 


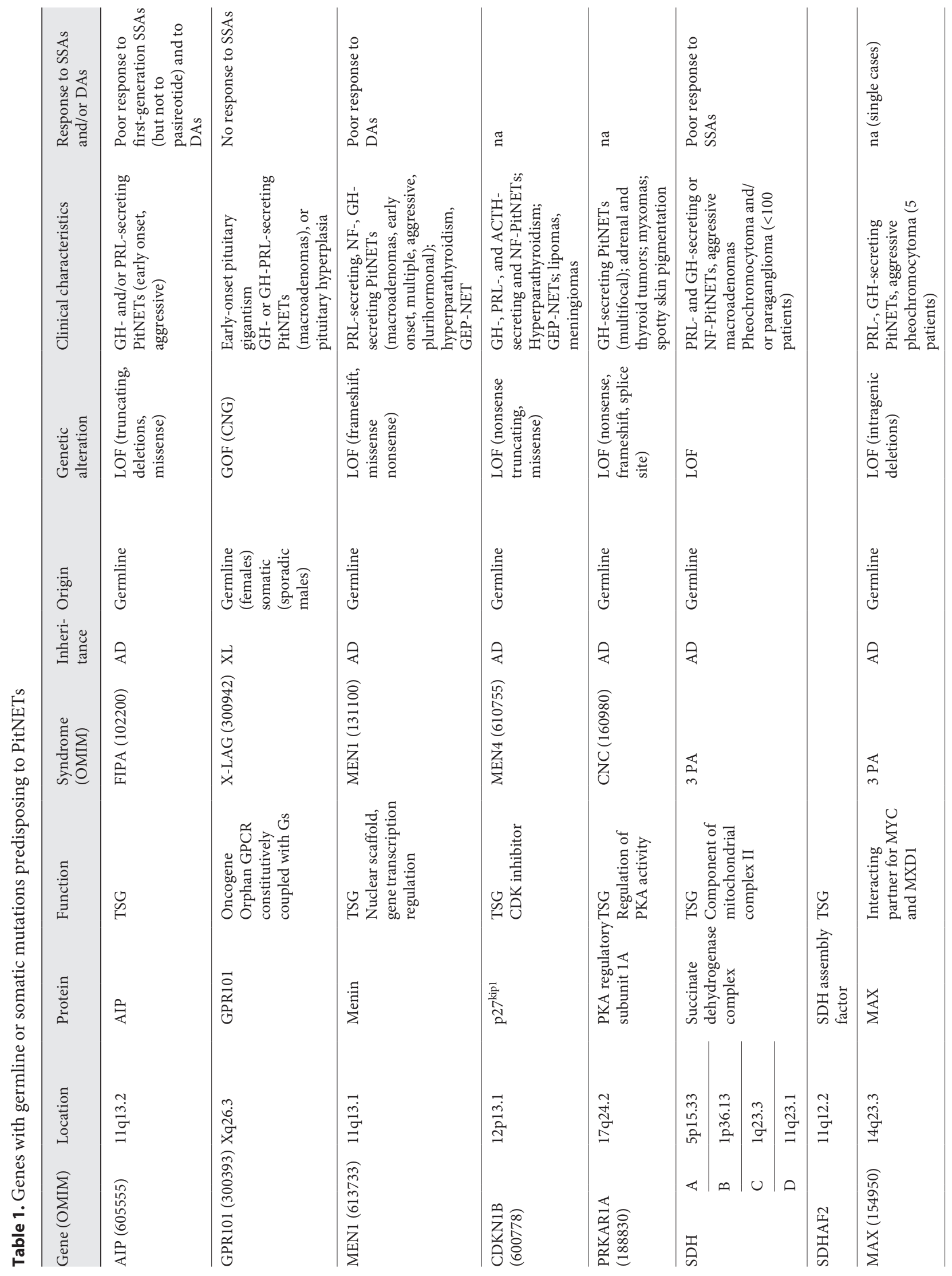




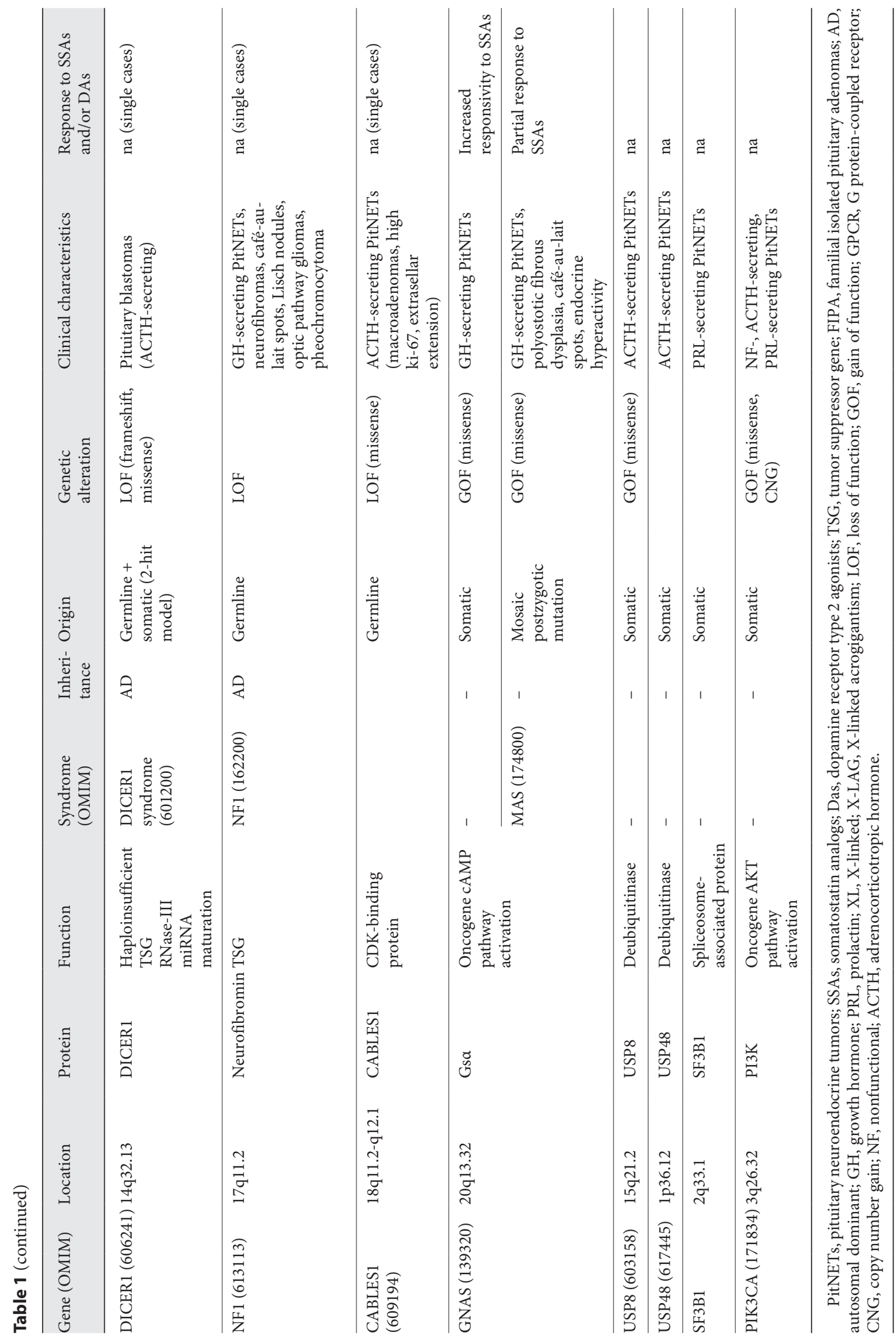


Fig. 1. Schematic representation of the genes involved in PitNET pathogenesis and affecting cAMP pathway activation (in red): AIP can bind PDE, PKA regulatory (R) subunit R1A, and PKA catalytic (C) subunit and can regulate the expression of the a subunit of the inhibitory $G$ protein $\left(\mathrm{Gi}_{2}\right)$; GPR101 is constitutively coupled with stimulatory $\mathrm{G}$ proteins, leading to AC activation and CAMP production; PRKA$\mathrm{R} 1 \mathrm{~A}$ encodes R1A that inhibits the binding of cAMP and activation of the $\mathrm{C}$ subunit; GNAS encodes the a subunit of the stimulatory $G$ proteins that when bound to GTP dissociates from $\beta \gamma$ and activates AC. The Gs $\alpha$ amino acid substitutions found in $\mathrm{GH}$ secreting PitNETs involve residues critical for GTPase activity, preventing hydrolysis of GTP and leading to constitutive activation of Gsa. PitNETs, pituitary neuroendocrine tumors; PDE, phosphodiesterase; AC, adenylyl cyclase; GH, growth hormone.

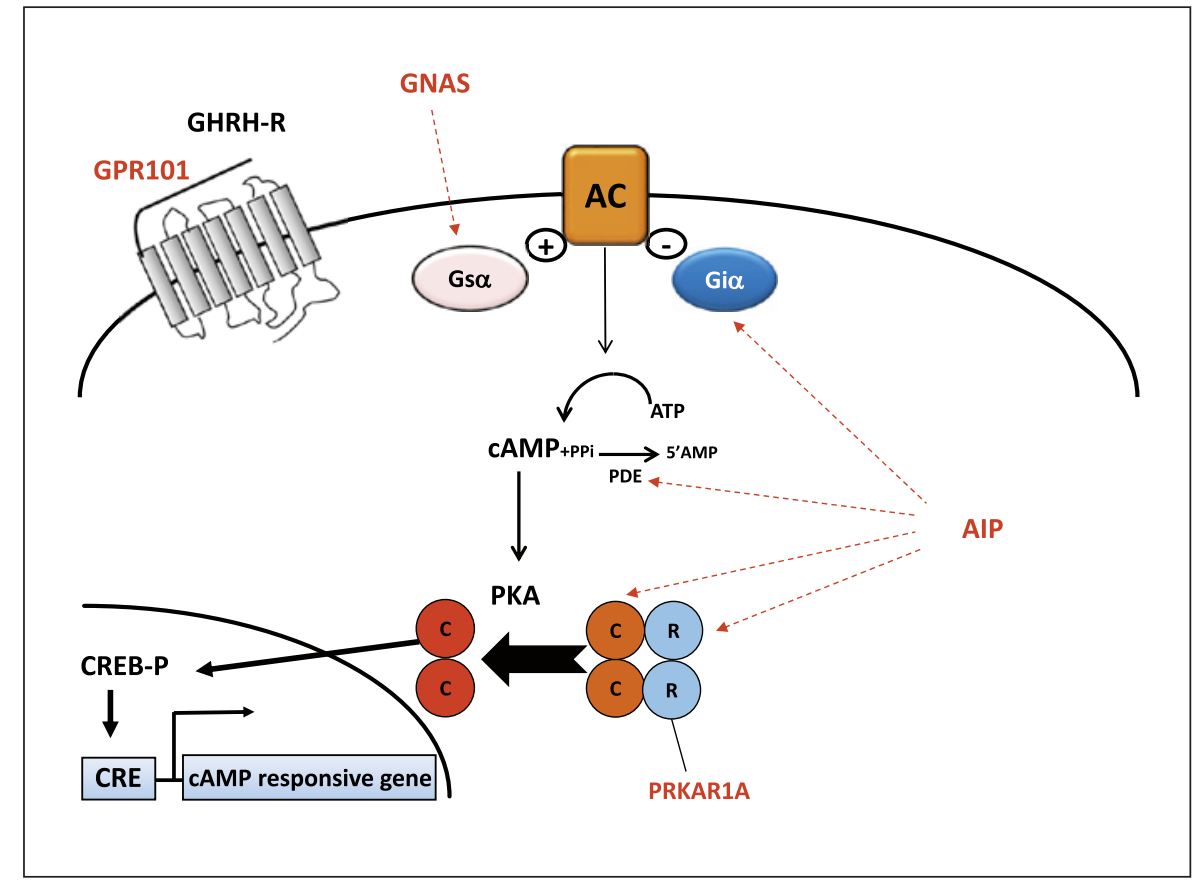

plasms. They can be classified into clinically nonfunctioning (NF) and hormone-secreting tumors, including growth hormone (GH)-, prolactin (PRL)-, and adrenocorticotropic hormone (ACTH)-secreting tumors $[1,3]$. Specific clinical features are determined by the hypersecreted hormone and/or by mass effects causing visual field deficits and neurologic manifestations.

The currently used drugs for the pharmacological treatment of PitNETs are somatostatin (SS) analogs (SSAs) and dopamine receptor type 2 (DRD2) agonists (DAs). First-generation SSAs octreotide and lanreotide represent the first-line medical treatment in acromegalic patients when surgery fails or for invasive or unresectable tumors, but about $50 \%$ of patients present resistance to treatment $[4,5]$. In patients with PRL-secreting PitNETs, the DA cabergoline represents the treatment of choice, inducing PRL normalization and tumor size reduction, but resistance to DAs is displayed in a subset of patients [6]. NF-PitNET medical therapy with SSAs or DAs has demonstrated a variable and often limited efficacy. PitNETs are characterized by a variable clinical behavior, ranging from benign, indolent lesions to recurrent, locally invasive, and resistant to multiple medical treatment tumors.

The great majority of pituitary tumors arise sporadically, without a known inheritable genetic mutation, but in about $5 \%$ of the cases, germline mutations have been identified as the pathogenetic cause. According to the mi- togenic effects played by cAMP in somatotroph cells, genes involved in GH-secreting PitNET pathogenesis often encode for proteins that contribute to increased cAMP signaling cascade (such as AIP, GPR101, PRKA$R 1 A$, and GNAS). Other genes are involved in the regulation of cell cycle progression (such as MEN1 and CDKN1B). PitNETs occurring in a familial setting present a more aggressive phenotype, with increased invasiveness and resistance to standard treatments. In sporadic tumors, no molecular markers have been identified predicting clinical behavior. Somatic mutations, found in a significant percentage of patients, have been involved in tumor formation, but are not correlated with its aggressive features. Alterations in the expression or activity of cytoskeleton and scaffold proteins in PitNETs have been recently correlated with resistance to SSAs and DAs and to invasive behavior.

\section{Pathogenesis of PitNETs: Germline and Somatic Mutations}

A small proportion of PitNETs, fewer than 5\%, develop secondary to germline mutations or to embryonic mutations leading to mosaicism, as part of syndromic diseases or as familial isolated pituitary adenomas. Tumors occurring in a familial setting are usually more aggressive, may present at a younger age, have a larger tumor size,
18

Neuroendocrinology 2022;112:15-33 DOI: $10.1159 / 000514862$
Spada et al. 
show increased invasiveness, and are often resistant to standard treatments with SSAs and DAs. In sporadic PitNETs, representing the vast majority of cases, somatic mutations found in a subgroup of patients can likely contribute to tumorigenesis.

\section{Germline Mutations}

No activating mutations of classical proto-oncogenes, as well as no loss of function mutations of tumor suppressor genes, have been found in PitNETs, with rare exceptions [7-9]. However, an increasing number of genes with germline mutations predisposing to PitNETs have been identified.

\section{AIP}

Germline loss of function mutations in the aryl hydrocarbon receptor (AhR)-interacting protein $(A I P)$ (Table 1) gene are found in about $20 \%$ of familial isolated pituitary adenoma families [10, 11], 50\% of families displaying acromegaly, and rarely in sporadically diagnosed PitNETs $(<4 \%)$, particularly in young patients, where the lack of family history is explained by incomplete penetrance rather than de novo mutations [12-14].

$A I P$ is a tumor suppressor gene with high and ubiquitous expression and conserved among species [15]. AIP is a co-chaperone able to bind multiple partners, and loss of some of these interactions may contribute to pituitary tumorigenesis. Among these, the interactions of AIP with components of the cAMP/PKA pathway are particularly interesting, due to the pathogenetic role of this pathway in GH-secreting PitNETs (Fig. 1) [16, 17]. Indeed, AIP can bind phosphodiesterases (PDE4A5 and PDE2A), PKA regulatory subunit R1A, and PKA catalytic subunit [18]. AIP might also affect the cAMP pathway acting upstream cAMP production, since it has been shown that AIP loss reduced the expression of the inhibitory G protein $\mathrm{Gai}_{2}$, possibly leading to an increased activity of adenylyl cyclase (Fig. 1) [19, 20].

The mechanisms involved in AIP pathogenetic effects might include other putative players in addition to the components of the cAMP pathway. AIP induces tumor shrinkage by positively regulating zinc finger protein $\mathrm{ZAC1}$ [21] that is also required for octreotide antiproliferative signaling [22]. Moreover, AIP stabilizes AhR, also called the dioxin receptor, an intracellular receptor and transcription factor regulating the response to halogenated aromatic hydrocarbons, by the formation of a complex with $\mathrm{Hsp} 90$ and $\mathrm{p} 23$ proteins that protect AhR from ubiquitination [23]. Nevertheless, AhR involvement in pituitary tumorigenesis remains to be demonstrated.

Genetic and Molecular Factors in PitNET

Pathogenesis and Behavior
AIP mutation-positive patients are characterized by early-onset and usually aggressive $\mathrm{GH}$-secreting PitNETs [11], often resistant to treatment with first-generation SSAs [24], but not necessarily to pasireotide [25] (Table 1). Even in the absence of mutations, AIP is frequently downregulated in sporadic GH-secreting PitNETs, in which low AIP is associated with reduced SST2 expression and with reduced responsiveness to first-generation SSAs as well $[24,26,27]$. Pretreatment with octreotide induced an increase of AIP expression, suggesting an AIP involvement in SST2 signal transduction $[21,28]$. In contrast, responsiveness to pasireotide, as well as SST5 expression, is not correlated with AIP expression levels [29].

\section{GPR101}

Duplications involving the GPR101 gene (Table 1) in the Xq26.3 region cause X-linked acrogigantism (X-LAG) [30], a very rare condition of early-onset pituitary gigantism. Patients with X-LAG display GH- or GH-PRL-secreting tumors or pituitary hyperplasia.

The GPR101 gene encodes a class A, rhodopsin-like, orphan G protein-coupled receptor (GPCR) [30-32]. GPR101 protein was found to be strongly expressed in the human normal pituitary during fetal development as well as in adolescence but not in adult pituitary, suggesting that its expression is induced during development and adolescence [33]. In PitNETs, GPR101 is not expressed in sporadic cases but is strongly overexpressed in the lesions of X-LAG patients [30, 31].

The molecular mechanism of pituitary tumorigenesis involves cAMP pathway activation. Indeed, GPR101 is constitutively coupled with stimulatory $\mathrm{G}$ proteins, leading to intracellular cAMP accumulation [30,34], with direct effects on somatotroph cell proliferation and GH secretion (Fig. 1). A recent study in transgenic mice has demonstrated that GPR101 constitutively activates not only $G_{s}$, but also $G_{q / 11}$ and $G_{12 / 13}$, leading to $G H$ secretion but not cell proliferation [35]. The pathogenetic mechanism may also involve the ability of GPR101 to increase GHRH secretion by the hypothalamus, accordingly to the elevated circulating GHRH levels described in some XLAG patients [30, 36, 37].

The clinical features of X-LAG patients include early onset of accelerated growth, starting from the first months of life, markedly elevated GH levels resulting in significantly increased IGF-1, concomitant hyperprolactinemia in $>80 \%$ of the patients, presence of acromegalic features at early age, increased appetite, female predominance, and a poor response to SSAs $[36,38,39]$. Since alterations of SST2 and AIP expression in X-LAG tumors have been

Neuroendocrinology 2022;112:15-33 DOI: $10.1159 / 000514862$ 
excluded [36], the molecular mechanisms underlying the pharmacological resistance to SSAs of X-LAG patients remain to be investigated.

\section{MEN1}

Germline heterozygous mutations in the MEN1 gene cause multiple endocrine neoplasia 1 (MEN1) (Table 1), an autosomal dominant disorder that presents with combination of endocrine and nonendocrine tumors. More than 1,500 MEN1 mutations distributed throughout the whole gene have been described, mainly frameshift, missense, and nonsense mutations [40,41] without a clear genotype-phenotype correlation $[42,43]$. De novo mutations occur in approximately $10 \%$ of patients, whereas most MEN1 patients have a positive family history for MEN1-associated manifestations. Somatic mutations in the MEN1 gene are not commonly found in sporadic PitNETs [44].

MEN1 is characterized by the occurrence in a patient of at least 2 of the 3 following disorders: hyperparathyroidism, gastroenteropancreatic-NETs, and PitNETs, reported in $30-40 \%$ of cases [42-44]. The most prevalent PitNET subtype is PRL-secreting (60-80\%), followed by NF-PitNETs (15-40\%), GH-secreting (5-10\%), and, rarely, ACTH-secreting [42-44].

Menin is a 610 -amino acid nuclear protein that interacts as a scaffold with various molecular partners involved in transcriptional regulation, genome stability, cell division, and proliferation [45]. Menin binds and inhibits JunD, a component of the AP1 transcription factor complex and negative regulator of RAS-dependent cell proliferation [46]. Another mechanism involved in menin-mediated antiproliferative effects is the recruitment of the mixed lineage leukemia protein to the promoters of the cyclin-dependent kinase inhibitor $1 \mathrm{~B}$ and $\mathrm{C}(\mathrm{CDKN} 1 \mathrm{~B}, \mathrm{C})$ and the interaction with the transcriptional coactivator lens epithelium-derived growth factor [47]. This event promotes the transcription of p27 and p57 $[48,49]$, crucial in regulating cell cycle progression in endocrine tissues. Moreover, menin binds cyclin-dependent kinase 4 (CDK4) [50], another regulator of the cell cycle during G1/S transition. PitNETs in MEN1 patients are frequently macroadenomas, arise at a younger age compared to sporadic tumors, can be multiple, plurihormonal, and are more aggressive, and display higher risk for resistance to treatment, especially in children with large PRL-secreting PitNETs.

\section{CDKN1B}

About $10 \%$ of patients with an MEN1-like phenotype do not harbor MEN1 pathogenetic variants, and germline mutations in the cyclin-dependent kinase inhibitor $1 \mathrm{~B}$ $(C D K N 1 B)$ gene, leading to multiple endocrine neoplasia type 4 (MEN4) [45], explain 1.5-3.7\% of them [51] (Table 1). No germline CDKN1B mutations were found in sporadic PitNETs [52]. PitNETs are found in about $37 \%$ of MEN4 reported cases and include GH-, ACTH-, and PRL-secreting and NF-PitNETs [51]. In addition, parathyroid tumors, other NETs, including adrenal and enteropancreatic tumors, as well as tumors involving nonendocrine organs, such as lipomas and meningiomas, have been reported in patients with MEN4 [53]. Due to the small number of patients so far reported, a comprehensive phenotype has not been established yet.

CDKN1B encodes $\mathrm{p} 27^{\mathrm{Kip} 1}$, a CDK inhibitor that prevents cell cycle progression from G1 to $S$ phase, thus acting as a tumor suppressor gene [54]. Interestingly, CD$\mathrm{KN} 1 \mathrm{~B}$ transcription is regulated by menin [48].

\section{PRKAR1A}

Carney's complex (CNC) is a familial endocrine neoplasia syndrome characterized by the presence of multiple cardiac and extra cardiac myxomas, spotty skin pigmentation, and different endocrine tumors, including $\mathrm{GH}$-secreting PitNETs, adrenocortical tumors, and thyroid adenomas [55-57]. Heterozygous loss of function mutations in the PRKAR1A gene account for over $70 \%$ of all cases of CNC [58] (Table 1). The large majority of PRKAR1A mutations are nonsense, frameshift, or splice site mutations which fail to produce a mutant protein due to mRNA degradation through the nonsense-mediated mRNA decay pathway [57].

Again, the pathogenetic mechanism of somatotroph tumorigenesis involves the activation of the promitotic cAMP pathway (Fig. 1). Indeed, the PRKAR1A gene encodes the type $1 \mathrm{~A}$ regulatory subunit (R1A) of PKA. PKA is a heterotetramer composed of 2 regulatory $(\mathrm{R})$ and 2 catalytic (C) subunits: $\mathrm{R}$ subunits inhibit the binding of cAMP and activation of the kinase activity of the $C$ subunit. Therefore, loss of R1A increases PKA responsiveness to cAMP, promoting somatotroph cell growth [17].

Mutations in this gene have not been detected in sporadic PitNETs [59-62]; however, other mechanisms have been identified leading to loss of R1A as well. Indeed, a reduced expression of the R1A protein in $\mathrm{GH}$-secreting tumors in the absence of inactivating mutations, but due to an increased degradation by proteasome, has been reported [61]. PRKACB gene locus copy number gain was found in a single patient with $\mathrm{CNC}$ that presented with abnormal skin pigmentation, myxomas, and acromegaly [63].
Spada et al. 
Other Genes Involved in PitNET Pathogenesis

Germline heterozygous mutations in genes encoding succinate dehydrogenase (SDH) subunits and the SDH complex assembly factor 2 protein (SDHAF2) have been described in patients with hereditary pheochromocytoma and paraganglioma (PPGL) (Table 1). The existence of a PPGL and pituitary adenoma association syndrome (3 PAs) suggests that pathogenic variants in these genes might be involved in pituitary tumorigenesis [64-66]. SDHx-mutated PitNETs are PRL- and GH-secreting or NF-PitNETs, frequently macroadenomas with an aggressive clinical course and with poor response to SSAs [6466].

$\mathrm{SDH}$ is a large enzymatic complex composed of $2 \mathrm{sub}-$ units which form the catalytic core (SDHA and SDHB), 2 subunits which are responsible for anchoring the complex to the mitochondrial membrane (SDHC and SDHD), and an associated assembly factor (SDHAF2). SDH is mainly involved in the electron transfer chain of the mitochondria, and it is responsible for the reversible enzymatic conversion of succinate into fumarate within the citric acid cycle. Although the pathogenetic mechanism is still poorly understood, it has been hypothesized that mutations in any of the genes encoding SDH subunits might impair the electron transfer chain, mimicking hypoxia, and lead to the accumulation of succinate. Increase of hypoxia-inducible factor-1 $\alpha$ induces resistance to apoptotic signals and enhances glycolysis, promoting tumorigenesis [67].

Recently, PitNETs have been also reported in 5 patients with pheochromocytomas harboring mutations in the MAX gene, another gene causing predisposition to familial PPGL [68-70] (Table 1). They include 3 PRLand $2 \mathrm{GH}$-secreting PitNETs. MAX is an interacting partner for MYC and MXD1, transcription factors involved in the regulation of cell proliferation and apoptosis [71]. However, the role of MAX in PitNETs pathogenesis has not been investigated, and a causal relationship between MAX mutations and pituitary tumorigenesis has yet to be proven. Other rare germline mutations recently discovered as potential factors involved in PitNET pathogenesis occur in DICER1, NF1, and CABLES genes (Table 1).

Mutations in the DICER1 gene cause DICER1 syndrome, characterized by a number of unusual tumors, both benign and malignant, such as pleuropulmonary blastoma, and pituitary blastomas, very rare embryonal tumors of the pituitary gland [72]. DICER1 encodes an RNA cleavage enzyme that cleaves precursor microRNA (miRNA) into mature miRNA [73]. miRNAs are regulatory proteins that control the expression and/or degrada- tion of specific RNA molecules. Pituitary blastomas develop in infancy, and all cases have been identified under the age of 24 months. The main clinical presentations of neonates are pressure symptoms due to the large tumor and signs and symptoms of Cushing's disease, with high mortality [74]. A recent screening for DICER1 variants in a large cohort of Cushing's disease patients demonstrated that DICER1 gene variants may contribute to the pathogenesis of nonsyndromic corticotropinomas [75].

GH-secreting PitNETs can rarely be part of neurofibromatosis type 1 , characterized by neurofibromas, caféau-lait macules, osseous lesions, Lisch nodules, and optic pathway gliomas [76]. Germline mutations in the $C A$ BLES1 (CDK5 and ABL enzyme substrate 1) gene have been found in few cases of ACTH-secreting PitNETs [77]. In corticotrophs, CABLES1 protein negatively regulates the cell cycle in response to glucocorticoids. In mutated tumors, markedly reduced nuclear expression of p27 was observed. These ACTH-secreting PitNETs were macroadenomas with high Ki-67 index and extrasellar extension.

\section{Somatic Mutations}

In sporadic PitNETs, somatic mutations accounting for a significant percentage of cases have been found. $\mathrm{Mu}-$ tations in the GNAS gene are the only ones to be causally linked to GH-secreting PitNET pathogenesis. Other recurrent somatic genetic alterations are found in USP8 and USP48 genes in ACTH-secreting PitNETs, in the SF3B1 gene in PRL-secreting PitNETs, and in PIK3AC genes in different types of pituitary tumors. Whole-exome/genome sequencing studies revealed no other recurrent somatic mutations but abnormalities of several different genes involved in calcium and cAMP signaling [78].

\section{GNAS}

The first mutational change associated with PitNETs was identified in the GNAS1 gene, now GNAS (Table 1), encoding the a subunit of the stimulatory heterotrimeric guanine nucleotide binding proteins ( $\mathrm{G}$ proteins) $(\mathrm{Gsa})$ (Fig. 1). Amino acid substitutions in exons 8 and 9, replacing either Arg 201 with Cys, His, or Ser or Gln 227 with Arg or Leu, are found in about $40 \%$ of GH-secreting PitNETs and rarely in other types of PitNETs [79, 80].

$\mathrm{G}$ proteins are composed of 3 different subunits $(\alpha, \beta$, and $\gamma$ ). The $\alpha$ subunit binds guanine nucleotides and acts as GTPase. Once activated, GPCRs facilitate the exchange of GTP for GDP on the a subunit, which in turn becomes active, dissociates from $\beta \gamma$, and then regulates downstream effector proteins. Among these, adenylyl cyclase is 
activated by Gs, with consequent accumulation of intracellular cAMP that exerts mitogenic effects in somatotrophs [17].

The mutations found in GH-secreting PitNETs involve residues critical for GTPase activity, thus preventing hydrolysis of GTP and leading to constitutive activation of Gsa. Gsa can be therefore considered the product of a proto-oncogene, converted into an oncogene ( $g s p)$ in those cells in which cAMP represents a mitogenic signal.

Gsp-positive tumors are benign, frequently very small, well differentiated, and densely granulated, in agreement with their hypersecretory activity. They are characterized by an increased responsivity to treatment with SSAs [8183], although no increase of SSTs has been described in these tumors [84-86]. Overall, $g s p$ mutations show a limited oncogenic potential and associate with a benign phenotype, with the only exception in a patient with a lethal prolactinoma, in which $g s p$ mutation represented the second hit for the transition from prolactinoma to acromegaly [87].

This reduced oncogenic potential could be explained by the existence of intracellular regulatory mechanisms in $g s p$-mutated tumors able to counteract the activation of the cAMP pathway, including an increased phosphodiesterase 4 (PDE4) activity $[88,89]$, an increased expression of CREB and inducible cAMP early repressor [90], and a reduced stability of the mutated Gsa protein [91].

Germline-activating mutations of the GNAS gene are considered lethal to the embryo [92], but activating mutations occurring as an early postzygotic event result in the mosaic disease McCune-Albright syndrome (MAS) (Table 1) [93]. This rare syndromic condition predisposes to acrogigantism and affects bones (polyostotic fibrous dysplasia), skin (cafe'-au-lait macules), and several endocrine tissues (endocrine hyperactivity), such as gonads, pituitary, thyroid, and adrenal cortex $[93,94]$. Most commonly, the onset of MAS is in early childhood. These tissue-specific effects are due to mosaic-activating mutations at the Arg201 residue. $10-25 \%$ of MAS patients develop $\mathrm{GH}$ excess, due to $\mathrm{GH}$-secreting PitNETs or hyperplasia, often accompanied by hyperprolactinemia [95].

It has been found that $g s p$ mutations are localized on the maternal allele in sporadic as well as in MAS GH-secreting PitNETs [96], since in somatotrophs, the Gsa transcript mainly derives from the maternal allele due to tissue-specific paternal imprinting $[97,98]$.

\section{USP8}

Somatic mutations in the USP8 (ubiquitin-specific protease 8 ) gene are found in $21-62 \%$ of ACTH-secreting
PitNETs [99-104] (Table 1), but not in other types of pituitary tumors $[78,100]$. USP8 is a deubiquitinating enzyme, and among its targets, the EGF receptor (EGFR) is crucial in the tumorigenic mechanism. Indeed, by deubiquitination, USP8 impairs EGFR proteosomal degradation, promoting EGFR recycling and signaling, in particular towards ERK phosphorylation that in corticotrophs results in an increased POMC transcription [99].

USP8 mutations cluster in the 14-3-3 protein binding motif (exon 14; residues 715-720). In particular, 4 mutations account for over $80 \%$ of the total number of mutations (S718del, P720R, S718P, and P720Q), and only 2 individual pathogenic variants (D721N and T735I) were outside the 14-3-3 binding motif. Since Ser718 and Pro720 are required for 14-3-3 binding, their substitution prevents USP8 interaction with 14-3-3, increasing the proteolytic cleavage of USP8, required for its catalytic activity $[99,100]$.

Recent studies showed that other possible substrates of USP8 are deregulated in USP8-mutated tumors, suggesting that they can contribute to ACTH-secreting PitNET pathogenesis [105]. USP8-mutated tumors are characterized by small size, high POMC expression, and ACTH secretion $[99,106]$. They are mostly found in women and associated with a greater probability of surgical remission than wild-type tumors $[99,106]$, although a higher risk of recurrence has been reported as well $[102,103]$. An increased expression of SST5 in USP8-mutated tumors has suggested a possible better responsiveness to pasireotide of this subgroup of corticotropinomas [101], but no studies have validated this hypothesis up to now. Interestingly, a de novo germline mutation of USP8 (S719P) was found in a young female patient with Cushing disease [107], supporting the key role of USP8 in ACTH-secreting PitNET pathogenesis.

\section{Somatic Mutations in Other Genes}

Mutations affecting another member of the ubiquitinspecific protease family, USP48, have been described in 23\% of USP8 wild-type ACTH-secreting PitNETs [108]. Differently from USP8, the pathogenetic mechanism does not involve ERK activation but the NF- $\kappa \mathrm{B}$ pathway, which is implicated in the $\mathrm{CRH}$-induced transcriptional activation of the POMC gene [108].

The same work described the somatic mutation V600E in BRAF in $16.4 \%$ of ACTH-secreting PitNETs [108]. BRAF mutant enhances the promoter activity and transcription of POMC. The authors found that primary corticotroph tumor cells harboring BRAF V600E are sensitive to the BRAF inhibitor vemurafenib [108]. As for
Spada et al. 
a

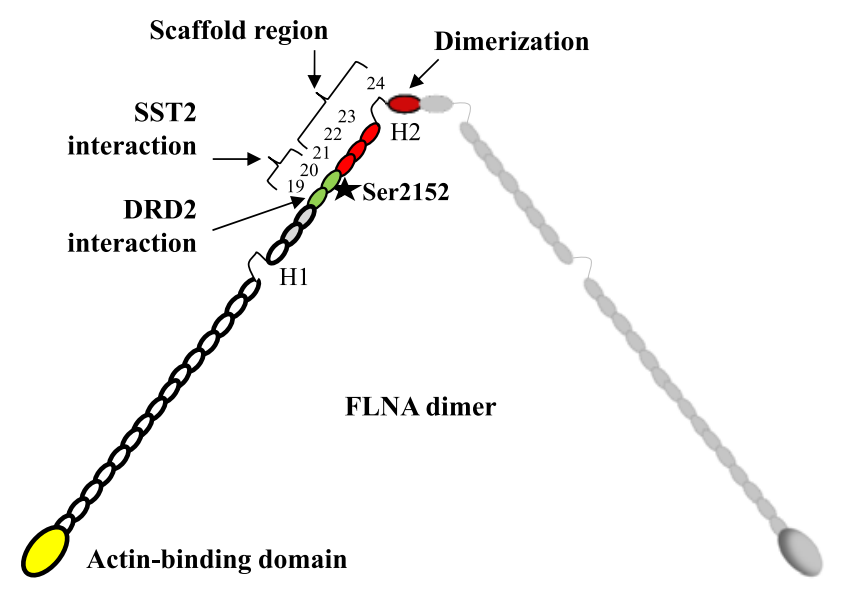

b

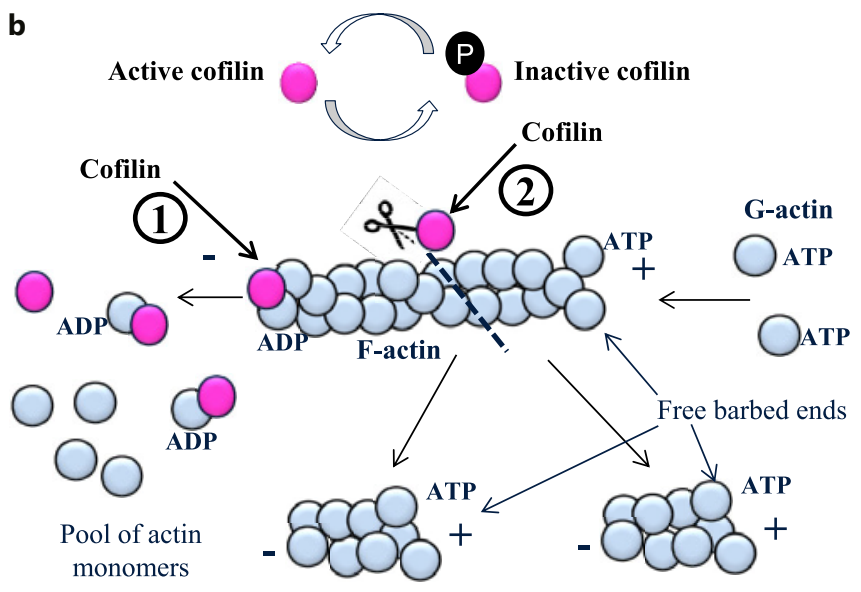

Fig. 2. a Schematic representation of an FLNA dimer. At the Nterminus, there is an ABD, followed by 24 immunoglobulin-like $\beta$-sandwich fold repeats of about 96 amino acidic residues each. The rod-1 domain (repeats 1-15), rod-2 domain (repeats 16-23), and repeat 24 are separated by hinge region $1(\mathrm{H} 1)$ and $2(\mathrm{H} 2)$. Green circles: repeats involved in DRD2/SST2 binding. Red circles: scaffold region. The repeat 24 mediates FLNA homodimerization. Repeat 20 contains the residue serine 2152 target of PKA phosphorylation. $\mathbf{b}$ Representation of the mechanism of action of

USP8, also BRAF and USP48 somatic mutations were not detected in other types of PitNETs, suggesting a specificity for ACTH-secreting PitNETs.

Recently, the somatic mutation $\mathrm{R} 625 \mathrm{H}$ in the gene encoding splicing factor 3 subunit B1 (SF3B1) was identified by whole-genome sequencing in 21 patients with PRL-secreting PitNETs [109]. In 227 PRL-secreting PitNETs, SF3B1 mutation $\mathrm{R} 625 \mathrm{H}$ was found in $19.8 \%$ of tumor tissue samples, whereas no SF3B1 mutations have been found in other types of PitNETs [109]. SF3B1-mutated PRL-secreting tumors displayed higher PRL levels and shorter progression-free survival compared to wild-type patients [109]. In vitro experiments showed that SF3B1 R625H enhanced proliferation and suppressed apoptosis of GH3 and MMQ cells. Interestingly, the authors found that SF3B1 R625H caused aberrant splicing of estrogen-related receptor gamma, which resulted in stronger binding of pituitary-specific positive transcription factor 1, leading to excessive estrogen-independent PRL transcription [109].

Activating somatic mutations of PIK3CA have been detected in different types of PitNETs, including ACTHand PRL-secreting and NF PitNETs $[110,111]$. This gene cofilin. Cofilin is able to bind both G-actin and F-actin and exerts 2 main biochemical functions: (1) it depolymerizes ADP-bound actin filaments near the pointed ends to supply a pool of free Gactin monomers for polymerization; (2) it severs actin filaments thus increasing the number of actin-free barbed ends, from which F-actin polymerizes. The main mechanism regulating cofilin activity is phosphorylation at Ser3 that prevents its ability to bind actin. FLNA, filamin A; ABD, actin-binding domain; G, globular; F, filamentous.

encodes the p110- $\alpha$ catalytic subunit of PI3K, and its activating mutations lead to constitutive activation of the AKT pathway. These mutations were associated with increased PitNET invasiveness [110].

\section{Clinical Behavior of Pituitary Tumors: The Role of Scaffold Proteins}

Although genetic findings provide insights into the clinical characteristics of mutant pituitary tumors, the genetic causes of sporadic and hereditary tumors are unknown in most cases, and the molecular basis of the tumor biological behavior, clinical presentations, and therapeutic responses remain to be investigated. In the last years, the expression and the activity of specific scaffold proteins have been correlated with pharmacological resistance and invasiveness of pituitary tumors.

In particular, 2 major cytoskeleton actin-binding proteins, filamin A (FLNA) and cofilin, as well as the scaffold proteins $\beta$-arrestins, emerged as key regulators of proper functioning of the molecular mechanisms that in pitu- 


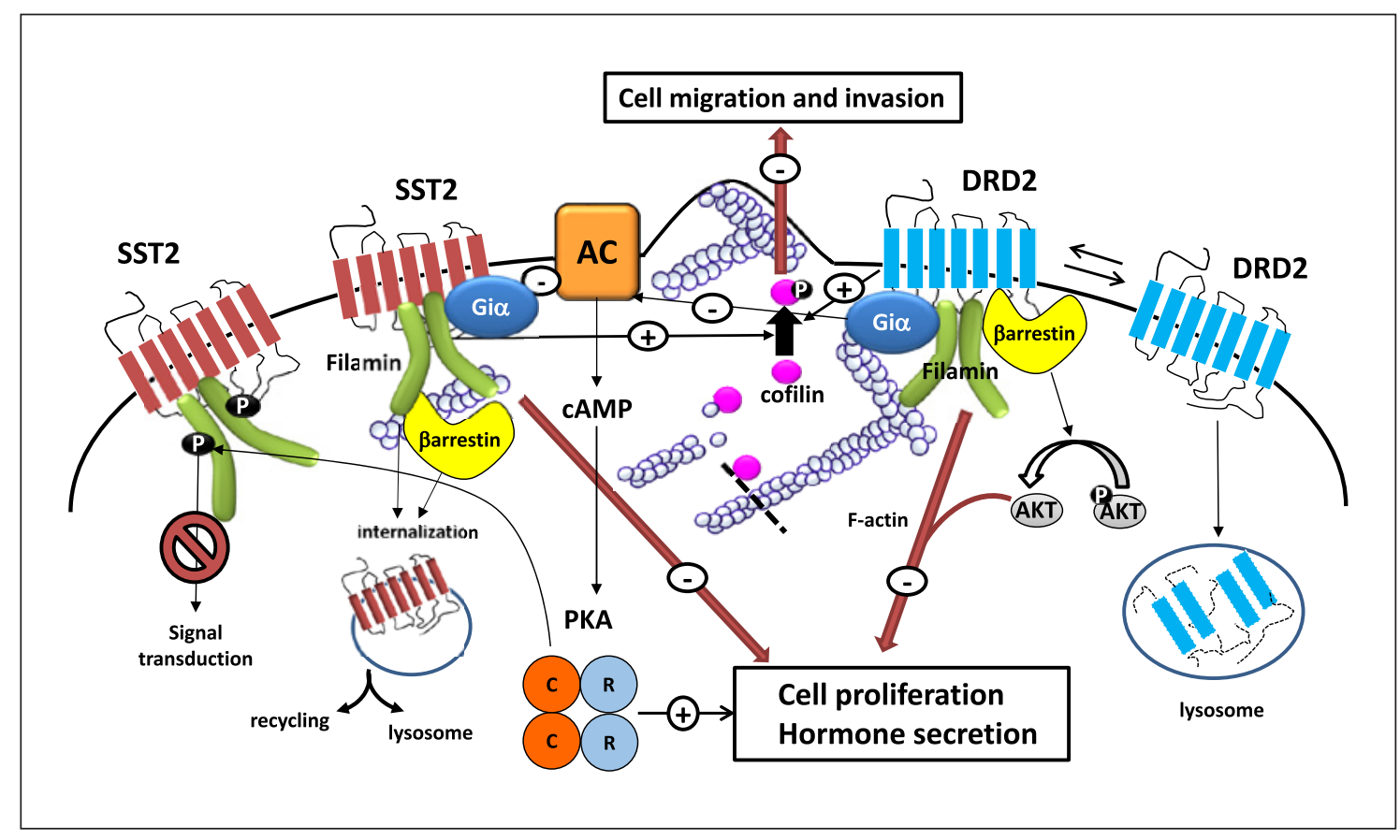

Fig. 3. Molecular factors underlying PitNET clinical behavior. Scaffold proteins FLNA, cofilin, and $\beta$-arrestins and their relationships with the SST2, DRD2, and CAMP pathway are represented. FLNA is required for SST2 internalization, recycling, and protection from lysosomal degradation after prolonged agonist stimulation (in GH-secreting PitNET cells) and for DRD2 cell membrane localization and protection against lysosomal degradation (in PRL-secreting PitNETs). Moreover, FLNA scaffold functions are required for an efficient DRD2 and SST2 signal transduction cascade leading to inhibition of cell proliferation, hormone secretion, and cell migration and invasion. However, when phosphorylated by PKA, FLNA becomes a signal termination protein that prevents

itary tumor cells are required to determine drug responsiveness. Cell cytoskeleton, once believed to be only a structural component of the cell, is now recognized as a complex, dynamic, and multifunctional network of protein filaments that plays several cellular function, ranging from cell movement and shape maintenance to cell differentiation, division, and intracellular transport. FLNA and cofilin are able to bind actin, the protein subunit that originates microfilaments by polymerization. Specifically, FLNA is involved in actin filament crosslinking, while cofilin in actin filament remodeling (Fig. 2a, b). $\beta$-Arrestin- 1 and -2 are versatile scaffold proteins that participate in GPCR desensitization, endocytosis, intracellular trafficking, and signal transduction, and alterations in their expression in PitNETs might have important consequences on the efficacy of medical therapy.
SST2 signaling. Cofilin phosphorylation is promoted by SST2 (in GH-secreting PitNET cells) and DRD2 (in NF-PitNET cells) and inhibits tumoral cell migration and invasion. FLNA is required for cofilin recruitment to SST2 and phosphorylation. $\beta$-Arrestins are involved in SST2 desensitization, internalization, and recycling, resulting in the modulation of patient responsiveness to SSAs treatment. $\beta$-Arrestin- 2 is required for DRD2-induced AKT dephosphorylation and proliferation inhibition in PRL-secreting and NF-PitNETs. PitNETs, pituitary neuroendocrine tumors; FLNA, filamin A; GH, growth hormone; PRL, prolactin; NF, nonfunctioning.

\section{Filamin A}

FLNA is a member of the family of filamins that also includes filamins B and C. FLNA is ubiquitously expressed and is the most abundant isoform [112]. FLNA gene is located on chromosome Xq28 [113]. In mice, the absence of the FLNA protein induces in males embryonic lethality and in females cardiac malformations and skeletal defects [114]. In humans, most hemizygous males harboring FLNA loss of function mutations die early during embryogenesis. In females, these mutations cause periventricular nodular heterotopia, a localized neuronal migration disorder, or other clinical disorders, called filaminopathies $[115,116]$ that also include congenital malformations induced by FLNA gain of function mutations [117, 118].

FLNA (2647 amino acids, $280 \mathrm{kDa}$ ) contains an actinbinding domain at the $\mathrm{N}$-terminus, followed by $24 \mathrm{immu}$ - 
noglobulin-like $\beta$-sandwich fold repeats of about 96 amino acidic residues each. Repeats 1-15 (rod-1 domain) and 1623 (rod-2 domain) are separated by a flexible hinge region (H1), and another hinge (H2) separates repeats 23 and 24. FLNA can be cleaved by calpain at both $\mathrm{H} 1$ and $\mathrm{H} 2$. A secondary actin-binding domain of lower affinity is located in the rod- 1 domain, whereas rod- 2 is the region involved in the interactions with partner proteins, including intracellular signaling molecules, kinases, and transcription factors. Repeat 24 is the self-association domain that mediates FLNA homodimerization. FLNA dimers crosslink perpendicular actin filaments, conferring membrane integrity and defending cells against mechanical stress $[119,120]$ (Fig. 2a). The relevance of FLNA in pituitary tumor biology resides in its ability to bind SST2 and DRD2, thus physically connecting these receptors with the actin cytoskeleton and allowing the formation of multiprotein complexes because of scaffold function of FLNA, as discussed below.

\section{FLNA Role in Regulating DRD2}

The first study establishing a correlation between pituitary tumor pharmacological resistance and alterations of actin-binding proteins was conducted in PRL-secreting tumors. The observation that low or absent DRD2 expression, associated with cabergoline resistance, is accompanied by low or absent FLNA protein expression [121] paved the way for subsequent in vitro experiments testing the role of FLNA in the regulation of DRD2 expression. FLNA gene silencing or overexpression in primary cultured prolactinoma cells induced corresponding modifications of DRD2 levels, suggesting a causal relationship between these 2 events. Moreover, FLNA was essential not only for DRD2 expression but also for signal transduction of dopamine inhibitory signals [121] (Fig. 3). Indeed, reduction of PRL secretion and ERK1/2 phosphorylation mediated by the DRD2 agonist in primary cultured human PRL-secreting cells were impaired after FLNA silencing, whereas DA-resistant prolactinomas lacking FLNA recovered responsiveness to the dopaminergic agonist when transfected with FLNA [121]. The mechanism by which FLNA regulates DRD2 expression was investigated in rat PRL-secreting pituitary tumor MMQ cells. FLNA was required for DRD2 targeting to the cell membrane, as well as to protect DRD2 against lysosomal degradation (Fig. 3) [121]. How FLNA controls DRD2 postendocytic fate towards recycling processes or lysosomal degradation remains to be investigated. A role for $\beta$-arrestins involved in DRD2 internalization and trafficking [122] can by hypothesized, since it has been demonstrated that these proteins are binding partners of FLNA [123].

Genetic and Molecular Factors in PitNET

Pathogenesis and Behavior
In HEK293 cells, FLNA regulates DRD2 internalization and recycling [124], supporting FLNA involvement in the regulation of the DRD2 route after endocytosis. A protective effect of FLNA from receptor degradation was also demonstrated for other receptors, including calcium-sensing receptor [125], calcitonin receptor [126], cystic fibrosis transmembrane conductance regulator [127], and the high-affinity IgG receptor FcgammaRI [128]. FLNA was required for efficient recycling of SST2 in GHsecreting PitNETs [129] and chemokine receptor CCR2 and $\beta 2$-adrenergic receptor [130].

The molecular events leading to FLNA-reduced expression in resistant tumors remain to be investigated. To date, no alterations in the FLNA gene CpG island with the highest probability to have regulatory functions have been found, excluding an epigenetic silencing [121].

Due to these essential functions of FLNA for DRD2 expression and signaling in lactotrophs, loss of FLNA expression and/or function may be one of the mechanisms involved in resistance of PRL-secreting PitNETs to dopaminergic drugs. FLNA expression was correlated with DRD2 expression also in GH-secreting PitNETs [131], suggesting that FLNA function in regulating DRD2 is conserved in different pituitary tumor types.

\section{FLNA Role in Regulating SST2}

Although FLNA can directly bind the SST2 first intracellular loop by its repeats 19-20 [132], FLNA protein expression did not correlate with SST2 expression in GH-secreting PitNET tissues [133], in striking contrast with data on DRD2 in prolactinomas [121]. In addition, FLNA was not required for localization of SST2 on the plasma membrane of human tumoral somatotroph cells [133], in agreement with data in melanoma cells [132]. However, single-molecule microscopy analysis in $\mathrm{CHO}$ cells recently showed that SST2 spatial arrangement and mobility at the plasma membrane are controlled by dynamic SST2-FLNA interactions [134]. Moreover, FLNA was required for the formation of SST2 clusters and their alignment along actin fibers in $\mathrm{CHO}$ cells. In GH-secreting PitNET cells, FLNA was essential for SST2 internalization upon agonist incubation (Fig. 3) [129]. Despite FLNA being a binding partner of $\beta$-arrestin-2, FLNA knockdown did not prevent the formation of $\beta$-arrestin-2-SST 2 complexes in GH 3 cells but significantly impaired SST2 loading into cytosolic vesicles positive for the early endocytic and recycling markers, Rab5 and 4, respectively, and prevented SST2 recycling to the cell membrane [129]. In addition, SST2-FLNA interaction resulted necessary to prevent activated SST2 lysosomal degradation and maintain SST2 stability after prolonged agonist stimu-

Neuroendocrinology 2022;112:15-33 DOI: $10.1159 / 000514862$ 
lation [133]. Overall, these data demonstrated that FLNA is a molecular platform able to connect SST2 with components of the machinery of intracellular trafficking, and that FLNA alterations might profoundly impact on the physiological processes of receptor internalization and recycling.

Moreover, FLNA scaffold functions are required for an efficient SST2 signal transduction cascade (Fig. 3). Indeed, in human GH-secreting PitNET primary cultured cells, silencing of FLNA abolished SST2-induced reduction of cyclin D1 and activation of caspase $3 / 7$, required for the antiproliferative and proapoptotic effects of SST2, respectively [133]. Overexpression of the dominant negative mutant FLNA21-24 (containing only FLNA repeats from 21 to 24, representing the scaffold domain of FLNA) in GH3 cells prevented SST2 effects on apoptosis and ERK1/2 inhibition, suggesting that FLNA scaffold properties are required for the recruitment of signal transduction molecules to activated SST2 [133].

These mechanisms could explain resistance to SSAs even if in presence of SST2. Indeed, the absence or reduced expression of FLNA determines the loss of coupling of SST2 with downstream signal transduction molecules.

In GH-secreting PitNETs, a positive correlation between FLNA and SST2 expression only existed in not SSA-pretreated patients who were controlled with SSAs, corroborating an FLNA involvement in SST2 regulation and signaling [131]. The same study revealed that in $\mathrm{GH}$ secreting PitNETs, FLNA expression was correlated with SST5 expression [131]. This observation suggests a possible contribution for FLNA in determining pasireotide responsiveness in PitNETs. In this regard, it would be of great interest to investigate FLNA role in the regulation of SST5 in ACTH-secreting PitNETs.

\section{FLNA Activity Modulation}

It is worth noting that the evaluation of FLNA protein or transcript expression levels usually detected by immunohistochemistry and qRT-PCR, respectively, does not take into account posttranslational modifications that are crucial in determining FLNA activity. One of the main mechanisms that controls FLNA functions is phosphorylation on Ser2152, in the repeat 20, that modifies FLNAbinding properties [135, 136], conformation [137], intracellular localization $[130,138]$, and its proteolytic cleavage by calpain [139-142].

In vitro experiments in GH-secreting PitNET cells showed that the activation of the CAMP/PKA pathway significantly increased FLNA phosphorylation at Ser2152 [143], with dramatic effects on its function. Indeed, the overexpression of a phoshomimicking FLNA S2152D mu- tant completely abolished SST2 signal transduction in GH3 cells [143]. This mutant interacts constitutively with SST2, but loses the ability to bind inhibitory $G$ proteins, leading to signal transduction termination (Fig. 3). Thus, although the expression of FLNA is a prerequisite for SST2 signaling, the evaluation of FLNA phosphorylation status is needed to establish whether FLNA is functioning as a scaffold protein allowing SST2 signal transduction or as a signal termination protein that prevents SSA efficacy. No data are available on the effects of FLNA phosphorylation on DRD2 functions.

Another mechanism that regulates FLNA binding to its interaction partners is alternative splicing that gives origin to different FLNA variants. In particular, FLNA splice variant-1 contains an internal deletion of 41 amino acids (residues 2127-2167) [144], located in the domain of interaction with SST2 and DRD2, and including Ser2152 target of phosphorylation, thus suggesting a potentially altered ability in binding SST2 and DRD2 and in functioning as a scaffold for their signaling. No data are available testing the expression of FLNA splice variant-1 in the pituitary. Further studies in a large series of patients evaluating FLNA expression as well as its phosphorylation level and its splicing variants are thus needed to validate FLNA as a marker able to predict PitNET responsiveness to medical treatment with SSAs and DAs.

\section{Cofilin}

Cofilin-1 (also called cofilin) belongs to the ADF/cofilin family, together with cofilin 2 (a muscle type of cofilin) and actin-depolymerizing factor or destrin (ADF), and represents the most abundant and ubiquitous member of this family. In mice, deletion of the cofilin gene is embryonic lethal, due to defects in proliferation, polarization, and migration of neural crest cells $[145,146]$.

Cofilin is a small protein of $19 \mathrm{kDa}$ able to bind both globular (G)-actin and filamentous (F)-actin. It contains an actin-depolymerizing factor homology (ADF-H) domain and a nuclear localization signal. Cofilin activity promotes cell migration, due to the dual action to depolymerize adenosine diphosphate-bound actin filaments near the pointed ends and to sever pre-existing actin filaments. The consequent increase of the number of both free G-actin monomers and actin-free barbed ends, from which F-actin polymerizes, promotes actin polymerization [147] (Fig. 2b). Cofilin activity is tightly regulated, and phosphorylation at Ser3 is the main regulatory mechanism [148]. This posttranslational modification prevents cofilin's ability to bind actin, thus inactivating cofilin. Ser3 phosphorylation is mediated by the Rho small GTPases, through a cascade of kinases, including PAK,
Spada et al. 
ROCK, and LIMK. Alterations of cofilin and its phosphorylation pathway have been described in human cancer, with potential effects on tumor development, progression, invasion, and metastasis (reviewed in [149]).

\section{Cofilin Role in NF-PitNET Invasiveness}

Recent data demonstrated a key role for cofilin in regulating the invasiveness of NF-PitNETs. In vitro experiments performed in the human NF-PitNET HP75 cell line showed that the overexpression of cofilin induced an increase of cell migration [150]. This effect was reproduced by the constitutively active cofilin phosphodeficient mutant S3A, but not phosphomimicking S3D [150], suggesting a promigratory action of dephosphorylated cofilin only (Fig. 3). Accordingly, S3A cofilin, but not S3D, colocalized with F-actin in membrane protrusions in HP75 cells [150].

Analysis of cofilin phosphorylation in human NF-PitNET tissues confirmed a correlation of cofilin phosphorylation status with tumor invasiveness [150]. Western blot analysis demonstrated higher phosphorylated cofilin (P-cofilin)/total cofilin ratio in noninvasive NF-PitNETs than in invasive tumors. Moreover, immunohistochemistry analysis showed high immunoreactivity for P-cofilin in noninvasive tumors and a low or absent $\mathrm{P}$-cofilin staining in invasive tumors [150].

Notably, the phosphorylation status of cofilin in NFPitNET cells can be regulated by DAs. In vitro experiments in primary NF-PitNET cultured cells demonstrated that the DRD2 agonist promotes a ROCK-dependent LIMK phosphorylation, which in turn increases cofilin phosphorylation [150]. The activation of this pathway induces a downstream inhibition of cell migration and invasion [150] (Fig. 3).

Overall, cofilin, and more precisely its phosphorylation status, might represent a potential new biomarker predictive of NF-PitNET invasiveness and recurrence. The effects of DAs in reducing cofilin activity and cell invasion need to be further investigated to provide useful information for the management of patients and the use of adjuvant therapies.

Cofilin Role in GH-Secreting PitNET Invasiveness

A crucial role of cofilin in regulating cell motility has been shown also in GH-secreting PitNET cells. In GH3 cells, transfection of S3D cofilin was able to reduce GH3 cell invasion, whereas no effect was observed after transfection of S3A or wild-type cofilin [151]. These results are in contrast with the promigratory effects of S3A cofilin observed in NF-PitNETs [150], suggesting that in different types of pituitary tumors, the mechanisms by which

Genetic and Molecular Factors in PitNET

Pathogenesis and Behavior cofilin activity is regulated and the consequent effects on actin cytoskeleton remodeling are different.

Similar to DRD2, SST2 was able to exert inhibitory effects on cell migration and cell invasion by activating RhoA and inducing a ROCK-mediated increase of cofilin phosphorylation in GH3 and primary cultured GH-secreting pituitary tumoral cells [151] (Fig. 3). The molecular mechanism employed by SST2 to activate the RhoA/ ROCK/cofilin pathway involves FLNA, as demonstrated by both FLNA genetic silencing and transfection of FLNA dominant negative mutants preventing FLNA binding to SST2 (FLNA 19-20) or to signaling molecules (FLNA 2124) $[151]$.

Confocal microscopy and co-immunoprecipitation assays demonstrated that upon agonist incubation, SST2 colocalized with FLNA and cofilin at the plasma membrane. Moreover, FLNA is essential for cofilin recruitment to SST2, as demonstrated by FLNA knockdown [151]. These data revealed that FLNA act as a scaffold promoting connections between SST2, molecular components of the cofilin pathway, and microfilaments, enabling a direct effect of SST2 on actin cytoskeleton dynamics.

\section{$\beta$-Arrestins}

In mammals, nonvisual $\beta$-arrestin- 1 and $\beta$-arrestin-2 are ubiquitously expressed adaptor proteins that function to regulate desensitization, internalization, trafficking, and signaling of a number of GPCRs [152, 153]. In brief, upon GPCR activation by agonist binding, the receptor is phosphorylated by $\mathrm{G}$ protein-coupled receptor kinases, allowing recruitment of $\beta$-arrestins. This leads to $G$ protein-mediated signal termination (desensitization), by sterically disrupting GPCR/G protein coupling. In order to mediate GPCR endocytosis, $\beta$-arrestins coordinately interact with components of the endocytotic machinery, such as clathrin, adaptor protein 2 (AP2), and phosphoinositides, targeting receptor to clathrin-coated pits. In addition, $\beta$-arrestins are also able of generating their own signal transduction pathways, independently from $G$ protein activation, by binding and regulating various signaling molecules, including ERK, JNK, p38, Akt, PI3 kinase, and RhoA [153]. Regarding pituitary tumors, $\beta$-arrestins have been implicated in the regulation of both SSTs and DRD2 internalization and/or signaling, with crucial implication on PitNET clinical behavior.

\section{$\beta$-Arrestins and SSA Responsiveness}

The different subtypes of SSTs differ in their patterns of $\beta$-arrestin mobilization and endosomal sorting [154]. Based on the agonist-induced arrestin-receptor binding 
properties, GPCRs can be classified in class A receptors, characterized by higher affinity for $\beta$-arrestin-2 than $\beta$-arrestin- 1 and a transient and weak $\beta$-arrestin-receptor interaction, and class $B$ receptors, with similar affinities for $\beta$-arrestin- 1 and -2 and strong $\beta$-arrestin-receptor interaction [155]. These properties affect the fate of the internalized receptors and the recycling rate. Indeed, class A receptors are directed to clathrin-coated pits where the complex with $\beta$-arrestin dissociates at or near the plasma membrane, whereas class $B$ receptors remain tightly associated with $\beta$-arrestin and they internalize as a stable unit into early endosomes [155].

SST2 has been classified as a class B receptor, since its activation results in a robust recruitment of both $\beta$-arrestin-1 and -2 and in a stable colocalization with $\beta$-arrestin in the same endocytic vesicles, while activated SST5 and SST3 only bind $\beta$-arrestin- 2 and rapidly dissociate $[154,156,157]$. On the contrary, SST1 and SST4 show a $\beta$-arrestin-independent trafficking [154].

In $\mathrm{GH}$-secreting pituitary cells, $\beta$-arrestin- 2 is essential for SST5 internalization. Indeed, the naturally occurring SST5 mutant R240W, found in an acromegalic patient resistant to treatment with octreotide [158], failed in recruiting $\beta$-arrestin-2 in the rat pituitary cell line GH3 and showed impaired ligand-induced internalization [156], as well as an altered signal transduction $[159,160]$. Regarding SST2, the recruitment of $\beta$-arrestin- 2 was not sufficient to ensure proper internalization and recycling, as demonstrated by the impairment of both these processes in GH3 cells silenced for FLNA, despite $\beta$-arrestin- 2 recruitment [129].

$\beta$-Arrestin expression in PitNETs might have an impact on their clinical behavior, affecting the efficacy of SSA (Fig. 3). Indeed, a low expression of $\beta$-arrestin-1, but not $\beta$-arrestin-2, transcripts in GH- and PRL-secreting PitNETs was correlated with better tumor responsiveness to octreotide in terms of GH suppression both in vitro and in vivo [161]. In acromegalic patients, low $\beta$-arrestin-1 and -2 mRNA expression and high SST $2 / \beta$-arrestins ratio were associated with responsiveness to long-term treatment with SSAs [162]. However, no correlation between $\beta$-arrestin-1 mRNA level and SSA response was found in a recent study [163].

\section{$\beta$-Arrestins and DA Responsiveness}

Although several studies demonstrated a role for $\beta$-arrestins in regulating DRD2 internalization and signaling [164], few data are available in pituitary tumor cells. Recently, our group showed that DRD2 antiproliferative signaling in PRL-secreting and NF-PitNETs re- quired the expression of $\beta$-arrestin-2 [165] (Fig. 3). DRD2 agonist BIM53097 induced a reduction of AKT phosphorylation in rat tumoral lactotroph cells MMQ and in a subset of human primary cultured NF-PitNET cells, characterized by in vitro responsiveness to $\mathrm{DRD} 2$ antimitotic effects and expression of $\beta$-arrestin-2 protein [165]. A causal role for $\beta$-arrestin- 2 was demonstrated by its genetic silencing that prevented DRD2 inhibitory effects on AKT and cell proliferation in MMQ cells. Accordingly, $\beta$-arrestin-2 transfection in unresponsive NF-PitNETs restored the ability of the DRD2 agonist to inhibit both AKT phosphorylation and cell growth [165]. The molecular mechanism involved has been demonstrated in the mouse striatum. Upon DRD2 stimulation, $\beta$-arrestin- 2 is recruited to the receptor and functions as a scaffold for the formation of a multiprotein complex containing AKT and its negative regulator, protein phosphatase $2 \mathrm{~A}$, allowing AKT dephosphorylation [166]. From these data, $\beta$-arrestin- 2 emerged as a potential biomarker predicting NF-PitNETs' responsiveness to treatment with DAs.

\section{Conclusions}

Genetic and molecular alterations so far identified in PitNETs contribute to determine tumor clinical behavior. The presence of germline mutations in specific genes predisposing to PitNET formation is generally associated with more aggressive, invasive, and drug-resistant tumors, but the vast majority of PitNETs are sporadic. Somatic mutations associated with PitNET pathogenesis have been identified in significant percentages of patients, even though mutated tumors showed a similar or even better clinical phenotype compared to wild-type ones.

Alterations of some specific cytoskeleton and/or scaffold proteins have been found to significantly affect PitNET pharmacological resistance and invasive behavior. However, standardized studies conducted in a large series of patients proving the clinical usefulness of these potential biomarkers are still lacking. Although several progresses have been made in understanding molecular mechanisms underlying pituitary tumorigenesis and PitNET clinical phenotype, further studies are needed to identify biomarkers predicting the behavior and the response to therapeutic treatments of PitNETs.

\section{Conflict of Interest Statement}

The authors have no conflicts of interest to declare.
Spada et al. 


\section{Funding Sources}

This work was supported by AIRC (Associazione Italiana Ricerca Cancro) grant to G.M. (IG 2017-20594), Italian Ministry of Health grant to G.M. (PE-2016-02361797), and Ricerca Corrente Funds from the Italian Ministry of Health and Progetti di Ricerca di Interesse Nazionale (PRIN) grant to E.P. (2017N8CK4K).

\section{Author Contributions}

Anna Spada: drafting the work, review and editing, supervision, and final approval of the version to be published. Giovanna Mantovani: drafting the work, review and editing, supervision, and final approval of the version to be published. Donatella Treppiedi: drafting the work, review, and final approval. Federica Mangili: drafting the work, review, and final approval. Rosa Catalano: drafting the work, review, and final approval. Giulia Carosi: drafting the work, review, and final approval. Elisa Sala: drafting the work, review, and final approval. Erika Peverelli: drafting the work, review and editing, supervision, and final approval of the version to be published.

\section{References}

1 Trouillas J, Jaffrain-Rea ML, Vasiljevic A, Raverot G, Roncaroli F, Villa C. How to classify the pituitary neuroendocrine tumors (PitNET)s in 2020. Cancers. 2020 Feb;12(2): 514.

2 Asa SL, Casar-Borota O, Chanson P, Delgrange E, Earls P, Ezzat S, et al. From pituitary adenoma to pituitary neuroendocrine tumor (PitNET): an International Pituitary Pathology Club proposal. Endocr Relat Cancer. 2017 Apr;24(4):C5-8.

3 Lloyd RV, Osamura RY, Klöppel G, Rosai J. WHO classification of tumours of endocrine organs. Chapter 1: tumors of the pituitary Gland. Lyon: WHO; 2017. p. 14-8.

4 Freda PU, Katznelson L, van der Lely AJ, Reyes CM, Zhao S, Rabinowitz D. Long-acting somatostatin analog therapy of acromegaly: a meta-analysis. J Clin Endocrinol Metab. 2005 Aug;90(8):4465-73.

5 Giustina A, Mazziotti G, Torri V, Spinello M, Floriani I, Melmed S. Meta-analysis on the effects of octreotide on tumor mass in acromegaly. PLoS One. 2012 May;7(5):e36411.

6 Molitch ME. Pharmacologic resistance in prolactinoma patients. Pituitary. 2005 Jan; 8(1):43-52.

7 Ewing I, Pedder-Smith S, Franchi G, Ruscica $M$, Emery M, Vax V, et al. A mutation and expression analysis of the oncogene BRAF in pituitary adenomas. Clin Endocrinol. 2007 Mar;66(3):348-52.

8 Karga HJ, Alexander JM, Hedley-Whyte ET, Klibanski A, Jameson JL. Ras mutations in human pituitary tumors. J Clin Endocrinol Metab. 1992 Apr;74(4):914-9.

9 Pei L, Melmed S, Scheithauer B, Kovacs K, Prager D. H-ras mutations in human pituitary carcinoma metastases. J Clin Endocrinol Metab. 1994 Apr;78(4):842-6.

10 Vierimaa $\mathrm{O}$, Georgitsi $\mathrm{M}$, Lehtonen $\mathrm{R}$, Vahteristo P, Kokko A, Raitila A, et al. Pituitary adenoma predisposition caused by germline mutations in the AIP gene. Science. 2006 May;312(5777):1228-30.

11 Hernández-Ramírez LC, Gabrovska P, Dénes J, Stals K, Trivellin G, Tilley D, et al. International FIPA consortium. Landscape of familial isolated and young-onset pituitary adeno- mas: prospective diagnosis in AIP mutation carriers. J Clin Endocrinol Metab. 2015 Sep; 100(9):E1242-54.

12 Beckers A, Aaltonen LA, Daly AF, Karhu A. Familial isolated pituitary adenomas (FIPA) and the pituitary adenoma predisposition due to mutations in the aryl hydrocarbon receptor interacting protein (AIP) gene. Endocr Rev. 2013 Apr;34(2):239-77.

13 Leontiou CA, Gueorguiev M, van der Spuy J, Quinton R, Lolli F, Hassan S, et al. The role of the aryl hydrocarbon receptor-interacting protein gene in familial and sporadic pituitary adenomas. J Clin Endocrinol Metab. 2008 Jun;93(6):2390-401.

14 Cazabat L, Bouligand J, Salenave S, Bernier M, Gaillard S, Parker F, et al. Germline AIP mutations in apparently sporadic pituitary adenomas: prevalence in a prospective singlecenter cohort of 443 patients. J Clin Endocrinol Metab. 2012 Apr;97(4):E663-70.

15 Trivellin G, Korbonits M. AIP and its interacting partners. J Endocrinol. 2011 Aug; 210(2):137-55.

16 Vitali E, Peverelli E, Giardino E, Locatelli M, Lasio GB, Beck-Peccoz P, et al. Cyclic adenosine $3^{\prime}-5^{\prime}$-monophosphate (cAMP) exerts proliferative and anti-proliferative effects in pituitary cells of different types by activating both cAMP-dependent protein kinase A (PKA) and exchange proteins directly activated by cAMP (Epac). Mol Cell Endocrinol. 2014 Mar;383(1-2):193-202.

17 Peverelli E, Mantovani G, Lania AG, Spada A. cAMP in the pituitary: an old messenger for multiple signals. J Mol Endocrinol. 2013 Dec; 52(1):R67-77.

18 Schernthaner-Reiter MH, Trivellin G, Stratakis CA. Interaction of AIP with protein kinase A (cAMP-dependent protein kinase). Hum Mol Genet. 2018 Aug;27(15):2604-13.

19 Tuominen I, Heliövaara E, Raitila A, Rautiainen MR, Mehine M, Katainen R, et al. AIP inactivation leads to pituitary tumorigenesis through defective Gai-cAMP signaling. Oncogene. 2015 Feb;34(9):1174-84.

20 Ritvonen E, Pitkänen E, Karppinen A, Vehkavaara $\mathrm{S}$, Demir $\mathrm{H}$, Paetau $\mathrm{A}$, et al. Impact of AIP and inhibitory $G$ protein alpha 2 proteins on clinical features of sporadic GH-secreting pituitary adenomas. Eur J Endocrinol. 2017 Feb;176(2):243-52.

21 Chahal HS, Trivellin G, Leontiou CA, Alband N, Fowkes RC, Tahir A, et al. Somatostatin analogs modulate AIP in somatotroph adenomas: the role of the ZAC1 pathway. J Clin Endocrinol Metab. 2012 Aug;97(8):E1411-20.

22 Theodoropoulou M, Zhang J, Laupheimer S, Paez-Pereda M, Erneux C, Florio T, et al. Octreotide, a somatostatin analogue, mediates its antiproliferative action in pituitary tumor cells by altering phosphatidylinositol 3-kinase signaling and inducing Zac1 expression. Cancer Res. 2006 Feb;66(3):1576-82.

23 Kazlauskas A, Poellinger L, Pongratz I. The immunophilin-like protein XAP2 regulates ubiquitination and subcellular localization of the dioxin receptor. J Biol Chem. 2000 Dec; 275(52):41317-24.

24 Daly AF, Tichomirowa MA, Petrossians P, Heliövaara E, Jaffrain-Rea ML, Barlier A, et al. Clinical characteristics and therapeutic responses in patients with germ-line AIP mutations and pituitary adenomas: an international collaborative study. J Clin Endocrinol Metab. 2010 Nov;95(11):E373-83.

25 Daly AF, Rostomyan L, Betea D, Bonneville JF, Villa C, Pellegata NS, et al. AIP-mutated acromegaly resistant to first-generation somatostatin analogs: long-term control with pasireotide LAR in two patients. Endocr Connect. 2019 Apr;8(4):367-77.

26 Kasuki L, Vieira Neto L, Wildemberg LE, Colli LM, de Castro M, Takiya CM, et al. AIP expression in sporadic somatotropinomas is a predictor of the response to octreotide LAR therapy independent of SSTR2 expression. Endocr Relat Cancer. 2012 May; 19(3):L25-9.

27 Oriola J, Lucas T, Halperin I, Mora M, Perales MJ, Alvarez-Escolá C, et al. Germline mutations of AIP gene in somatotropinomas resistant to somatostatin analogues. Eur J Endocrinol. 2012 Dec;168(1):9-13.

28 Jaffrain-Rea ML, Rotondi S, Turchi A, Occhi G, Barlier A, Peverelli E, et al. Somatostatin analogues increase AIP expression in somatotropinomas, irrespective of Gsp mutations. Endocr Relat Cancer. 2013 Sep;20(5):753-66. 
29 Iacovazzo D, Carlsen E, Lugli F, Chiloiro S, Piacentini S, Bianchi A, et al. Factors predicting pasireotide responsiveness in somatotroph pituitary adenomas resistant to firstgeneration somatostatin analogues: an immunohistochemical study. Eur J Endocrinol. 2016 Feb;174(2):241-50.

30 Trivellin G, Daly AF, Faucz FR, Yuan B, Rostomyan L, Larco DO, et al. Gigantism and acromegaly due to Xq26 microduplications and GPR101 mutation. N Engl J Med. 2014 Dec; 371(25):2363-74.

31 Trivellin G, Hernández-Ramírez LC, Swan J, Stratakis CA. An orphan G-protein-coupled receptor causes human gigantism and/or acromegaly: molecular biology and clinical correlations. Best Pract Res Clin Endocrinol Metab. 2018 Mar;32(2):125-40.

32 Trivellin G, Faucz FR, Daly AF, Beckers A, Stratakis CA. Hereditary endocrine tumours: current state-of-the-art and research opportunities: GPR101, an orphan GPCR with roles in growth and pituitary tumorigenesis. Endocr Relat Cancer. 2020 Aug;27(8):T87-97.

33 Trivellin G, Bjelobaba I, Daly AF, Larco DO, Palmeira L, Faucz FR, et al. Characterization of GPR101 transcript structure and expression patterns. J Mol Endocrinol. 2016 Aug; 57(2):97-111.

34 Bates B, Zhang L, Nawoschik S, Kodangattil S, Tseng E, Kopsco D, et al. Characterization of Gpr101 expression and G-protein coupling selectivity. Brain Res. 2006 May;1087(1):1-14.

35 Abboud D, Daly AF, Dupuis N, Bahri MA, Inoue A, Chevigné A, et al. GPR101 drives growth hormone hypersecretion and gigantism in mice via constitutive activation of Gs and Gq/11. Nat Commun. 2020 Sep;11(1):4752.

36 Beckers A, Lodish MB, Trivellin G, Rostomyan L, Lee M, Faucz FR, et al. X-linked acrogigantism syndrome: clinical profile and therapeutic responses. Endocr Relat Cancer. 2015 Jun;22(3):353-67.

37 Daly AF, Lysy PA, Desfilles C, Rostomyan L, Mohamed A, Caberg JH, et al. GHRH excess and blockade in X-LAG syndrome. Endocr Relat Cancer. 2016 Mar;23(3):161-70.

38 Iacovazzo D, Caswell R, Bunce B, Jose S, Yuan B, Hernández-Ramírez LC, et al. Germline or somatic GPR101 duplication leads to Xlinked acrogigantism: a clinico-pathological and genetic study. Acta Neuropathol Commun. 2016 Jun;4(1):56.

39 Rostomyan L, Daly AF, Petrossians P, Nachev E, Lila AR, Lecoq AL, et al. Clinical and genetic characterization of pituitary gigantism: an international collaborative study in $208 \mathrm{pa}$ tients. Endocr Relat Cancer. 2015 Oct;22(5): 745-57.

40 Lemos MC, Thakker RV. Multiple endocrine neoplasia type 1 (MEN1): analysis of 1336 mutations reported in the first decade following identification of the gene. Hum Mutat. 2008 Jan;29(1):22-32.

41 Concolino P, Costella A, Capoluongo E. Multiple endocrine neoplasia type 1 (MEN1): an update of 208 new germline variants reported in the last nine years. Cancer Genet. 2016 JanFeb;209(1-2):36-41.

42 Verges B, Boureille F, Goudet P, Murat A, Beckers A, Sassolas G, et al. Pituitary disease in MEN type 1 (MEN1): data from the FranceBelgium MEN1 multicenter study. J Clin Endocrinol Metab. 2002 Feb;87(2):457-65

43 de Laat JM, Dekkers OM, Pieterman CR, Kluijfhout WP, Hermus AR, Pereira AM, et al. Long-term natural course of pituitary tumors in patients with MEN1: results from the DutchMEN1 Study Group (DMSG). J Clin Endocrinol Metab. 2015 Sep;100(9): 3288-96

44 Trouillas J, Labat-Moleur F, Sturm N, Kujas M, Heymann MF, Figarella-Branger D, et al. PitNETs and hyperplasia in multiple endocrine neoplasia type 1 syndrome (MEN1): a case-control study in a series of 77 patients versus 2509 non-MEN1 patients. Am J Surg Pathol. 2008 Apr;32(4):534-43.

45 Thakker RV. Multiple endocrine neoplasia type 1 (MEN1) and type 4 (MEN4). Mol Cell Endocrinol. 2014 Apr;386(1-2):2-15.

46 Agarwal SK, Guru SC, Heppner C, Erdos MR, Collins RM, Park SY, et al. Menin interacts with the AP1 transcription factor JunD and represses JunD-activated transcription. Cell. 1999 Jan;96(1):143-52.

47 Yokoyama A, Cleary ML. Menin critically links MLL proteins with LEDGF on cancerassociated target genes. Cancer Cell. 2008 Jul; 14(1):36-46.

48 Milne TA, Hughes CM, Lloyd R, Yang Z, Rozenblatt-Rosen O, Dou Y, et al. Menin and MLL cooperatively regulate expression of cyclin-dependent kinase inhibitors. Proc Natl Acad Sci U S A. 2005 Jan;102(3):749-54.

$49 \mathrm{Wu}$ T, Hua X. Menin represses tumorigenesis via repressing cell proliferation. Am J Cancer Res. 2011 May;1(6):726-39.

50 Gillam MP, Nimbalkar D, Sun L, Christov K, Ray D, Kaldis P, et al. MEN1 tumorigenesis in the pituitary and pancreatic islet requires Cdk4 but not Cdk2. Oncogene. 2015 Feb; 34(7):932-8.

51 Alrezk R, Hannah-Shmouni F, Stratakis CA. MEN4 and CDKN1B mutations: the latest of the MEN syndromes. Endocr Relat Cancer. 2017 Oct;24(10):T195-208.

52 Stratakis CA, Tichomirowa MA, Boikos S, Azevedo MF, Lodish M, Martari M, et al. The role of germline AIP, MEN1, PRKAR1A, CD$\mathrm{KN} 1 \mathrm{~B}$ and $\mathrm{CDKN} 2 \mathrm{C}$ mutations in causing pituitary adenomas in a large cohort of children, adolescents, and patients with genetic syndromes. Clin Genet. 2010 Nov;78(5):457-63.

53 Frederiksen A, Rossing M, Hermann P, Ejersted C, Thakker RV, Frost M. Clinical features of multiple endocrine neoplasia type 4: novel pathogenic variant and review of published cases. J Clin Endocrinol Metab. 2019 Sep; 104(9):3637-46.

54 Hengst L, Dulic V, Slingerland JM, Lees E, Reed SI. A cell cycle-regulated inhibitor of cyclin-dependent kinases. Proc Natl Acad Sci U S A. 1994 Jun;91(12):5291-5.
55 Carney JA. The Carney complex (myxomas, spotty pigmentation, endocrine overactivity, and schwannomas). Dermatol Clin. 1995 Jan; 13(1):19-26.

56 Stratakis CA, Kirschner LS, Carney JA. Clinical and molecular features of the Carney complex: diagnostic criteria and recommendations for patient evaluation. J Clin Endocrinol Metab. 2001 Sep;86(9):4041-6.

57 Kirschner LS, Sandrini F, Monbo J, Lin JP, Carney JA, Stratakis CA. Genetic heterogeneity and spectrum of mutations of the PRKAR1A gene in patients with the carney complex. Hum Mol Genet. 2000 Dec;9(20):303746.

58 Bertherat J, Horvath A, Groussin L, Grabar S, Boikos S, Cazabat L, et al. Mutations in regulatory subunit type $1 \mathrm{~A}$ of cyclic adenosine $5^{\prime}$-monophosphate-dependent protein kinase (PRKAR1A): phenotype analysis in 353 patients and 80 different genotypes. J Clin Endocrinol Metab. 2009 Jun;94(6): 2085-91.

59 Kaltsas GA, Kola B, Borboli N, Morris DG, Gueorguiev M, Swords FM, et al. Sequence analysis of the PRKAR1A gene in sporadic somatotroph and other pituitary tumours. Clin Endocrinol. 2002 Oct;57(4):443-8.

60 Sandrini F, Kirschner LS, Bei T, Farmakidis C, Yasufuku-Takano J, Takano K, et al. PRKAR1A, one of the Carney complex genes, and its locus (17q22-24) are rarely altered in pituitary tumours outside the Carney complex. J Med Genet. 2002 Dec;39(12):e78.

61 Lania AG, Mantovani G, Ferrero S, Pellegrini C, Bondioni S, Peverelli E, et al. Proliferation of transformed somatotroph cells related to low or absent expression of protein kinase a regulatory subunit $1 \mathrm{~A}$ protein. Cancer Res. 2004 Dec;64(24):9193-8.

62 Mantovani G, Bondioni S, Ferrero S, Gamba B, Ferrante E, Peverelli E, et al. Effect of cyclic adenosine $3^{\prime}, 5^{\prime}$-monophosphate/protein kinase a pathway on markers of cell proliferation in nonfunctioning pituitary adenomas. J Clin Endocrinol Metab. 2005 Dec;90(12): 6721-4.

63 Forlino A, Vetro A, Garavelli L, Ciccone R, London E, Stratakis CA, et al. PRKACB and Carney complex. N Engl J Med. 2014 Mar; 370(11):1065-7.

64 O’Toole SM, Dénes J, Robledo M, Stratakis CA, Korbonits M. 15 years of paraganglioma: the association of pituitary adenomas and phaeochromocytomas or paragangliomas. Endocr Relat Cancer. 2015 Aug;22(4):T10522.

65 Xekouki P, Brennand A, Whitelaw B, Pacak K, Stratakis CA. The 3PAs: an update on the association of pheochromocytomas, paragangliomas, and pituitary tumors. Horm Metab Res. 2019 Jul;51(7):419-36.

66 Mougel G, Lagarde A, Albarel F, Essamet W, Luigi P, Mouly C, et al. Germinal defects of SDHx genes in patients with isolated pituitary adenoma. Eur J Endocrinol. 2020 Oct;183(4): 369-79. 
67 Favier J, Gimenez-Roqueplo AP. Pheochromocytomas: the (pseudo)-hypoxia hypothesis. Best Pract Res Clin Endocrinol Metab. 2010 Dec;24(6):957-68.

68 Daly AF, Castermans E, Oudijk L, Guitelman MA, Beckers P, Potorac I, et al. Pheochromocytomas and pituitary adenomas in three patients with MAX exon deletions. Endocr Relat Cancer. 2018 May;25(5):L37-42.

69 Roszko KL, Blouch E, Blake M, Powers JF, Tischler AS, Hodin R, et al. Case report of a prolactinoma in a patient with a novel MAX mutation and bilateral pheochromocytomas. J Endocr Soc. 2017 Oct;1(11): 1401-7.

70 Kobza AO, Dizon S, Arnaout A. Case report of bilateral pheochromocytomas due to a novel max mutation in a patient known to have a pituitary prolactinoma. AACE Clin Case Rep. 2018 Jul;4(6):e453-6.

71 Atchley WR, Fitch WM. Myc and Max: molecular evolution of a family of proto-oncogene products and their dimerization partner. Proc Natl Acad Sci U S A. 1995 Oct;92(22): 10217-21.

72 Hill DA, Ivanovich J, Priest JR, Gurnett CA, Dehner LP, Desruisseau D, et al. DICER1 mutations in familial pleuropulmonary blastoma. Science. 2009 Aug;325(5943):965.

73 Foulkes WD, Priest JR, Duchaine TF. DICER1: mutations, microRNAs and mechanisms. Nat Rev Cancer. 2014 Oct;14(10):66272.

74 Scheithauer BW, Horvath E, Abel TW, Robital Y, Park SH, Osamura RY, et al. Pituitary blastoma: a unique embryonal tumor. Pituitary. 2012 Sep;15(3):365-73.

75 Martínez de LaPiscina I, Hernández-Ramírez LC, Portillo N, Gómez-Gila AL, Urrutia I, Martínez-Salazar R, et al. Rare germline DICER1 variants in pediatric patients with Cushing's disease: what is their role? Front Endocrinol. 2020 Jul;11:433.

76 Hirbe AC, Gutmann DH. Neurofibromatosis type 1: a multidisciplinary approach to care. Lancet Neurol. 2014 Aug;13(8):834-43.

77 Hernandez-Ramirez LC, Gam R, Valdes N, Lodish MB, Pankratz N, Balsalobre A, et al. Loss-of-function mutations in the CABLES1 gene are a novel cause of Cushing's disease. Endocrine-Related Cancer. 2017 Aug;24(8) 379-92.

78 Ronchi CL, Peverelli E, Herterich S, Weigand I, Mantovani G, Schwarzmayr T, et al. Landscape of somatic mutations in sporadic $\mathrm{GH}$ secreting pituitary adenomas. Eur J Endocrinol. 2016 Mar;174(3):363-72.

79 Vallar L, Spada A, Giannattasio G. Altered Gs and adenylate cyclase activity in human GHsecreting pituitary adenomas. Nature. 1987 Dec;330(6148):566-8.

80 Landis CA, Masters SB, Spada A, Pace AM, Bourne HR, Vallar L. GTPase inhibiting mutations activate the alpha chain of Gs and stimulate adenylyl cyclase in human pituitary tumours. Nature. 1989 Aug;340(6236):6926.
81 Spada A, Arosio M, Bochicchio D, Bazzoni N, Vallar L, Bassetti M, et al. Clinical, biochemical, and morphological correlates in patients bearing growth hormone-secreting pituitary tumors with or without constitutively active adenylyl cyclase. J Clin Endocrinol Metab. 1990 Dec;71(6):1421-6.

82 Adams EF, Brockmeier S, Friedmann E, Roth M, Buchfelder M, Fahlbusch R. Clinical and biochemical characteristics of acromegalic patients harboring gsp-positive and gsp-negative pituitary tumors. Neurosurgery. 1993 Aug;33(2):198-203.

83 Efstathiadou ZA, Bargiota A, Chrisoulidou A, Kanakis G, Papanastasiou L, Theodoropoulou $\mathrm{A}$, et al. Impact of gsp mutations in somatotroph pituitary adenomas on growth hormone response to somatostatin analogs: a meta-analysis. Pituitary. 2015 Dec;18(6):8617

84 Barlier A, Gunz G, Zamora AJ, Morange-Ramos I, Figarella-Branger D, Dufour H, et al. Pronostic and therapeutic consequences of Gs alpha mutations in somatotroph adenomas. J Clin Endocrinol Metab. 1998 May; 83(5):1604-10.

85 Barlier A, Pellegrini-Bouiller I, Gunz G, Zamora AJ, Jaquet P, Enjalbert A. Impact of gsp oncogene on the expression of genes coding for Gsalpha, Pit-1, Gi2alpha, and somatostatin receptor 2 in human somatotroph adenomas: involvement in octreotide sensitivity. J Clin Endocrinol Metab. 1999 Aug;84(8): 2759-65.

86 Corbetta S, Ballaré E, Mantovani G, Lania A, Losa M, Di Blasio AM, et al. Somatostatin receptor subtype 2 and 5 in human GH-secreting pituitary adenomas: analysis of gene sequence and mRNA expression. Eur J Clin Invest. 2001 Mar;31(3):208-14.

87 Lania AG, Ferrero S, Pivonello R, Mantovani G, Peverelli E, Di Sarno A, et al. Evolution of an aggressive prolactinoma into a growth hormone secreting pituitary tumor coincident with GNAS gene mutation. J Clin Endocrinol Metab. 2010 Jan;95(1):13-7.

88 Lania A, Persani L, Ballaré E, Mantovani S, Losa M, Spada A. Constitutively active Gs alpha is associated with an increased phosphodiesterase activity in human growth hormone-secreting adenomas. J Clin Endocrinol Metab. 1998 May;83(5):1624-8.

89 Persani L, Lania A, Borgato S, Filopanti M, Mantovani G, Conti M, et al. Relevant cAMPspecific phosphodiesterase isoforms in human pituitary: effect of Gsa mutations. J Clin Endocrinol Metab. 2001 Aug; 86(8):3795800.

90 Peri A, Conforti B, Baglioni-Peri S, Luciani $\mathrm{P}$, Cioppi F, Buci L, et al. Expression of cyclic adenosine $3^{\prime}, 5^{\prime}$-monophosphate (cAMP)responsive element binding protein and inducible-cAMP early repressor genes in growth hormone-secreting pituitary adenomas with or without mutations of the Gsa gene. J Clin Endocrinol Metab. 2001 May; 86(5):2111-7.
91 Ballaré E, Mantovani S, Lania A, Di Blasio AM, Vallar L, Spada A. Activating mutations of the Gs alpha gene are associated with low levels of Gs alpha protein in growth hormone-secreting tumors. J Clin Endocrinol Metab. 1998 Dec;83(12):438690.

92 Aldred MA, Trembath RC. Activating and inactivating mutations in the human GNAS1 gene. Hum Mutat. 2000 Sep;16(3): 183-9.

93 Weinstein LS, Shenker A, Gejman PV, Merino MJ, Friedman E, Spiegel AM. Activating mutations of the stimulatory $\mathrm{G}$ protein in the McCune-Albright syndrome. N Engl J Med. 1991 Dec;325(24):1688-95.

94 Schwindinger WF, Francomano CA, Levine MA. Identification of a mutation in the gene encoding the alpha subunit of the stimulatory $\mathrm{G}$ protein of adenylyl $\mathrm{cy}$ clase in McCune-Albright syndrome. Proc Natl Acad Sci U S A. 1992 Jun;89(11): 5152-6.

95 Vasilev V, Daly AF, Thiry A, Petrossians P, Fina F, Rostomyan L, et al. McCune-Albright syndrome: a detailed pathological and genetic analysis of disease effects in an adult patient. J Clin Endocrinol Metab. 2014 Oct;99(10): E2029-38.

96 Mantovani G, Bondioni S, Lania AG, Corbetta S, de Sanctis L, Cappa M, et al. Parental origin of Gsalpha mutations in the McCune-Albright syndrome and in isolated endocrine tumors. Clin Endocrinol Metab. 2004 Jun;89(6):30079.

97 Hayward BE, Barlier A, Korbonits M, Grossman $A B$, Jacquet $P$, Enjalbert $A$, et al. Imprinting of the $\mathrm{G}(\mathrm{s})$ alpha gene GNAS1 in the pathogenesis of acromegaly. J Clin Invest. 2001 Mar;107(6):R31-6.

98 Mantovani G, Ballare E, Giammona E, BeckPeccoz P, Spada A. The gsalpha gene: predominant maternal origin of transcription in human thyroid gland and gonads. J Clin Endocrinol Metab. 2002 Oct;87(10):473640.

99 Reincke M, Sbiera S, Hayakawa A, Theodoropoulou M, Osswald A, Beuschlein F, et al. Mutations in the deubiquitinase gene USP8 cause Cushing's disease. Nat Genet. 2015 Jan;47(1):31-8

100 Ma ZY, Song ZJ, Chen JH, Wang YF, Li SQ, Zhou LF, et al. Recurrent gain-of-function USP8 mutations in Cushing's disease. Cell Res. 2015 Mar;25(3):306-17.

101 Hayashi K, Inoshita N, Kawaguchi K, Ibrahim Ardisasmita A, Suzuki H, Fukuhara N, et al. The USP8 mutational status may predict drug susceptibility in corticotroph adenomas of Cushing's disease. Eur J Endocrinol. 2016 Feb;174(2):213-26.

102 Losa M, Mortini P, Pagnano A, Detomas M, Cassarino MF, Pecori Giraldi F. Clinical characteristics and surgical outcome in USP8-mutated human adrenocorticotropic hormone-secreting pituitary adenomas. Endocrine. $2019 \mathrm{Feb} ; 63(2): 240-6$. 
103 Albani A, Pérez-Rivas LG, Dimopoulou C, Zopp S, Colón-Bolea P, Roeber S, et al. The USP8 mutational status may predict longterm remission in patients with Cushing's disease. Clin Endocrinol. 2018 Jun 29. Epub ahead of print.

104 Sesta A, Cassarino MF, Terreni M, Ambrogio AG, Libera L, Bardelli D, et al. Ubiquitinspecific protease 8 mutant corticotrope adenomas present unique secretory and molecular features and shed light on the role of ubiquitylation on ACTH processing. Neuroendocrinology. 2020 Jan;110(1-2):119-29.

105 Weigand I, Knobloch L, Flitsch J, Saeger W, Monoranu CM, Höfner K, et al. Impact of USP8 gene mutations on protein deregulation in Cushing disease. J Clin Endocrinol Metab. 2019 Jul;104(7):2535-46.

106 Sbiera S, Kunz M, Weigand I, Deutschbein T, Dandekar T, Fassnacht M. The new genetic landscape of Cushing's disease: deubiquitinases in the spotlight. Cancers. 2019 Nov;11(11):1761.

107 Cohen M, Persky R, Stegemann R, Hernández-Ramírez LC, Zeltser D, Lodish MB, et al. Germline USP8 mutation associated with pediatric Cushing disease and other clinical features: a new syndrome. J Clin Endocrinol Metab. 2019 Oct;104(10):4676-82.

108 Chen J, Jian X, Deng S, Ma Z, Shou X, Shen $\mathrm{Y}$, et al. Identification of recurrent USP48 and BRAF mutations in Cushing's disease. Nat Commun. 2018 Aug;9(1):3171.

109 Li C, Xie W, Rosenblum JS, Zhou J, Guo J, Miao Y, et al. Somatic SF3B1 hotspot mutation in prolactinomas. Nat Commun. 2020 May 19;11(1):2506.

110 Lin Y, Jiang X, Shen Y, Li M, Ma H, Xing M, et al. Frequent mutations and amplifications of the PIK3CA gene in pituitary tumors. Endocr Relat Cancer. 2009 Mar;16(1):301-10.

111 Murat CB, Braga PB, Fortes MA, Bronstein $\mathrm{MD}$, Corrêa-Giannella ML, Giorgi RR. Mutation and genomic amplification of the PIK3CA proto-oncogene in pituitary adenomas. Braz J Med Biol Res. 2012 Sep;45(9): 851-5.

112 Feng Y, Walsh CA. The many faces of filamin: a versatile molecular scaffold for cell motility and signalling. Nat Cell Biol. 2004 Nov;6(11):1034-8.

113 van der Flier A, Sonnenberg A. Structural and functional aspects of filamins. Biochim Biophys Acta. 2001 Apr;1538(2-3):99-117.

114 Hart AW, Morgan JE, Schneider J, West K, McKie L, Bhattacharya S, et al. Cardiac malformations and midline skeletal defects in mice lacking filamin A. Hum Mol Genet. 2006 Aug; 15(16):2457-67.

115 Fox JW, Lamperti ED, Ekşioğlu YZ, Hong SE, Feng Y, Graham DA, et al. Mutations in filamin 1 prevent migration of cerebral cortical neurons in human periventricular heterotopia. Neuron. 1998 Dec;21(6): 1315-25.

116 Wade EM, Halliday BJ, Jenkins ZA, O'Neill AC, Robertson SP. The X-linked filaminop- athies: synergistic insights from clinical and molecular analysis. Hum Mutat. 2020 May; 41(5):865-83.

117 Robertson SP, Twigg SR, Sutherland-Smith AJ, Biancalana V, Gorlin RJ, Horn D, et al. Localized mutations in the gene encoding the cytoskeletal protein filamin A cause diverse malformations in humans. Nat Genet. 2003 Apr;33(4):487-91.

118 Robertson SP. Filamin A: phenotypic diversity. Curr Opin Genet Dev. 2005 Jun;15(3): 301-7.

119 Stossel TP, Condeelis J, Cooley L, Hartwig $\mathrm{JH}$, Noegel A, Schleicher M, et al. Filamins as integrators of cell mechanics and signalling. Nat Rev Mol Cell Biol. 2001 Feb;2(2): 138-45.

120 Nakamura F, Osborn TM, Hartemink CA, Hartwig JH, Stossel TP. Structural basis of filamin A functions. J Cell Biol. 2007 Dec; 179(5):1011-25.

121 Peverelli E, Mantovani G, Vitali E, Elli FM, Olgiati L, Ferrero S, et al. Filamin-A is essential for dopamine $\mathrm{d} 2$ receptor expression and signaling in tumorous lactotrophs. J Clin Endocrinol Metab. 2012 Mar;97(3): 967-77.

122 Kim KM, Valenzano KJ, Robinson SR, Yao WD, Barak LS, Caron MG. Differential regulation of the dopamine D2 and D3 receptors by $\mathrm{G}$ protein-coupled receptor kinases and beta-arrestins. J Biol Chem. 2001 Oct; 276(40):37409-14.

123 Scott MG, Pierotti V, Storez H, Lindberg E, Thuret A, Muntaner O, et al. Cooperative regulation of extracellular signal-regulated kinase activation and cell shape change by filamin A and beta-arrestins. Mol Cell Biol. 2006 May;26(9):3432-45.

124 Zheng M, Zhang X, Sun N, Min C, Zhang X, Kim KM. RalA employs GRK2 and $\beta$-arrestins for the filamin A-mediated regulation of trafficking and signaling of dopamine D2 and D3 receptor. Biochim Biophys Acta. 2016 Aug;1863(8):2072-83.

125 Zhang M, Breitwieser GE. High affinity interaction with filamin A protects against calcium-sensing receptor degradation. J Biol Chem. 2005 Mar;280(12):11140-6.

126 Seck T, Baron R, Horne WC. Binding of filamin to the C-terminal tail of the calcitonin receptor controls recycling. J Biol Chem. 2003 Mar;278(12):10408-16.

127 Thelin WR, Chen Y, Gentzsch M, Kreda SM, Sallee JL, Scarlett CO, et al. Direct interaction with filamins modulates the stability and plasma membrane expression of CFTR. J Clin Invest. 2007 Feb;117(2):364-74.

128 Beekman JM, van der Poel CE, van der Linden JA, van den Berg DL, van den Berghe PV, van de Winkel JG, et al. Filamin A stabilizes Fc gamma RI surface expression and prevents its lysosomal routing. J Immunol. 2008 Mar;180(6):3938-45.

129 Treppiedi D, Mangili F, Giardino E, Catalano R, Locatelli M, Lania AG, et al. Cytoskeleton protein filamin $\mathrm{A}$ is required for effi- cient somatostatin receptor type 2 internalization and recycling through Rab5 and Rab4 sorting endosomes in tumor somatotroph cells. Neuroendocrinology. 2020; $110(7-8): 642-52$

130 Pons M, Izquierdo I, Andreu-Carbó M, Garrido $\mathrm{G}$, Planagumà $\mathrm{J}$, Muriel $\mathrm{O}$, et al. Phosphorylation of filamin A regulates chemokine receptor CCR2 recycling. J Cell Sci. 2017 Jan;130(2):490-501.

131 Coelho MCA, Vasquez ML, Wildemberg LE, Vázquez-Borrego MC, Bitana L, Camacho AHDS, et al. Clinical significance of filamin A in patients with acromegaly and its association with somatostatin and dopamine receptor profiles. Sci Rep. 2019 Feb; 9(1):1122.

132 Najib S, Saint-Laurent N, Estève JP, Schulz S, Boutet-Robinet E, Fourmy D, et al. A switch of $G$ protein-coupled receptor binding preference from phosphoinositide 3-kinase (PI3K)-p85 to filamin A negatively controls the PI3K pathway. Mol Cell Biol. 2012 Mar;32(5):1004-16.

133 Peverelli E, Giardino E, Treppiedi D, Vitali E, Cambiaghi V, Locatelli M, et al. Filamin A (FLNA) plays an essential role in somatostatin receptor 2 (SST2) signaling and stabilization after agonist stimulation in human and rat somatotroph tumor cells. Endocrinology. 2014 Aug;155(8):2932-41.

134 Treppiedi D, Jobin ML, Peverelli E, Giardino E, Sungkaworn T, Zabel U, et al. Single-molecule microscopy reveals dynamic FLNA interactions governing SSTR2 clustering and internalization. Endocrinology. 2018 Aug; 159(8):2953-65.

135 Chen HS, Kolahi KS, Mofrad MR. Phosphorylation facilitates the integrin binding of filamin under force. Biophys J. 2009 Dec; 97(12):3095-104.

136 Sato T, Ishii J, Ota Y, Sasaki E, Shibagaki Y, Hattori S. Mammalian target of rapamycin (mTOR) complex 2 regulates filamin A-dependent focal adhesion dynamics and cell migration. Genes Cells. 2016 Jun;21(6):579-93.

137 Ithychanda SS, Fang X, Mohan ML, Zhu L, Tirupula KC, Naga Prasad SV, et al. A mechanism of global shape-dependent recognition and phosphorylation of filamin by protein kinase A. J Biol Chem. 2015 Mar; 290(13):8527-38.

138 Szeto SG, Williams EC, Rudner AD, Lee JM. Phosphorylation of filamin A by Cdk1 regulates filamin A localization and daughter cell separation. Exp Cell Res. 2015 Jan;330(2): 248-66.

139 Zhang Z, Lawrence J, Stracher A. Phosphorylation of platelet actin binding protein protects against proteolysis by calcium dependent sulfhydryl protease. Biochem Biophys Res Commun. 1988 Feb;151(1):355-60.

140 Chen M, Stracher A. In situ phosphorylation of platelet actin-binding protein by cAMPdependent protein kinase stabilizes it against proteolysis by calpain. J Biol Chem. 1989 Aug;264(24):14282-9. 
141 Jay D, Stracher A. Expression in Escherichia coli, phosphorylation with cAMP-dependent protein kinase and proteolysis by calpain of a 71-kDa domain of human endothelial actin binding protein. Biochem Biophys Res Commun. 1997 Mar;232(2):555-8.

142 Bedolla RG, Wang Y, Asuncion A, Chamie K, Siddiqui S, Mudryj MM, et al. Nuclear versus cytoplasmic localization of filamin A in prostate cancer: immunohistochemical correlation with metastases. Clin Cancer Res. 2009 Feb;15(3):788-96.

143 Peverelli E, Giardino E, Mangili F, Treppiedi D, Catalano R, Ferrante E, et al. cAMP/PKAinduced filamin A (FLNA) phosphorylation inhibits SST2 signal transduction in GH-secreting pituitary tumor cells. Cancer Lett. 2018 Oct;435:101-9.

144 Pentikäinen U, Jiang P, Takala H, Ruskamo S, Campbell ID, Ylänne J. Assembly of a filamin four-domain fragment and the influence of splicing variant- 1 on the structure. J Biol Chem. 2011 Jul;286(30):26921-30.

145 Gurniak CB, Perlas E, Witke W. The actin depolymerizing factor $\mathrm{n}$-cofilin is essential for neural tube morphogenesis and neural crest cell migration. Dev Biol. 2005 Feb; 278(1):231-41.

146 Bellenchi GC, Gurniak CB, Perlas E, Middei S, Ammassari-Teule M, Witke W. N-cofilin is associated with neuronal migration disorders and cell cycle control in the cerebral cortex. Genes Dev. 2007 Sep;21(18):234757.

147 Bravo-Cordero JJ, Magalhaes MA, Eddy RJ, Hodgson L, Condeelis J. Functions of cofilin in cell locomotion and invasion. Nat Rev Mol Cell Biol. 2013 Jul;14(7):405-15.

148 Agnew BJ, Minamide LS, Bamburg JR. Reactivation of phosphorylated actin depolymerizing factor and identification of the regulatory site. J Biol Chem. 1995 Jul;270(29): 17582-7.

149 Shishkin S, Eremina L, Pashintseva N, Kovalev L, Kovaleva M. Cofilin-1 and other ADF/ cofilin superfamily members in human malignant cells. Int J Mol Sci. 2016 Dec;18(1): 10.
150 Peverelli E, Giardino E, Treppiedi D, Locatelli M, Vaira V, Ferrero S, et al. Dopamine receptor type 2 (DRD2) inhibits migration and invasion of human tumorous pituitary cells through ROCK-mediated cofilin inactivation. Cancer Lett. 2016 Oct;381(2):27986.

151 Peverelli E, Giardino E, Treppiedi D, Catalano R, Mangili F, Locatelli M, et al. A novel pathway activated by somatostatin receptor type 2 (SST2): inhibition of pituitary tumor cell migration and invasion through cytoskeleton protein recruitment. Int $\mathrm{J}$ Cancer. 2018 May;142(9):1842-52.

152 Reiter E, Lefkowitz RJ. GRKs and beta-arrestins: roles in receptor silencing, trafficking and signaling. Trends Endocrinol Metab. 2006 May-Jun;17(4):159-65.

153 DeWire SM, Ahn S, Lefkowitz RJ, Shenoy SK. Beta-arrestins and cell signaling. Annu Rev Physiol. 2007;69:483-510.

154 Tulipano G, Stumm R, Pfeiffer M, Kreienkamp HJ, Höllt V, Schulz S. Differential beta-arrestin trafficking and endosomal sorting of somatostatin receptor subtypes. J Biol Chem. 2004 May;279(20):21374-82.

155 Oakley RH, Laporte SA, Holt JA, Caron MG, Barak LS. Differential affinities of visual arrestin, beta arrestin1, and beta arrestin2 for $\mathrm{G}$ protein-coupled receptors delineate two major classes of receptors. J Biol Chem. 2000 Jun;275(22):17201-10.

156 Peverelli E, Mantovani G, Calebiro D, Doni A, Bondioni S, Lania A, et al. The third intracellular loop of the human somatostatin receptor 5 is crucial for arrestin binding and receptor internalization after somatostatin stimulation. Mol Endocrinol. 2008 Mar; 22(3):676-88

157 Cambiaghi V, Vitali E, Morone D, Peverelli E, Spada A, Mantovani G, et al. Identification of human somatostatin receptor 2 domains involved in internalization and signaling in QGP-1 pancreatic neuroendocrine tumor cell line. Endocrine. 2017 Apr;56(1): 146-57.

158 Ballarè E, Persani L, Lania AG, Filopanti M, Giammona E, Corbetta S, et al. Mutation of somatostatin receptor type 5 in an acromegalic patient resistant to somatostatin analog treatment. J Clin Endocrinol Metab. 2001 Aug;86(8):3809-14.
159 Peverelli E, Lania AG, Mantovani G, BeckPeccoz P, Spada A. Characterization of intracellular signaling mediated by human somatostatin receptor 5: role of the DRY motif and the third intracellular loop. Endocrinology. 2009 Jul;150(7):3169-76.

160 Peverelli E, Busnelli M, Vitali E, Giardino E, Galés C, Lania AG, et al. Specific roles of G(i) protein family members revealed by dissecting SST5 coupling in human pituitary cells. J Cell Sci. 2013 Jan;126(Pt 2):638-44.

161 Gatto F, Feelders R, van der Pas R, Kros JM, Dogan F, van Koetsveld PM, et al. $\beta$-Arrestin 1 and 2 and $G$ protein-coupled receptor kinase 2 expression in pituitary adenomas: role in the regulation of response to somatostatin analogue treatment in patients with acromegaly. Endocrinology. 2013 Dec;154(12):4715-25.

162 Gatto F, Biermasz NR, Feelders RA, Kros JM, Dogan F, van der Lely AJ, et al. Low beta-arrestin expression correlates with the responsiveness to long-term somatostatin analog treatment in acromegaly. Eur J Endocrinol. 2016 May;174(5):651-62.

163 Puig-Domingo M, Gil J, Sampedro-Nuñez $M$, Jordà $M$, Webb SM, Serra G, et al. Molecular profiling for acromegaly treatment: a validation study. Endocr Relat Cancer. 2020 Jun;27(6):375-89.

164 Beaulieu JM, Gainetdinov RR. The physiology, signaling, and pharmacology of dopamine receptors. Pharmacol Rev. 2011 Mar; 63(1):182-217.

165 Mangili F, Giardino E, Treppiedi D, Barbieri AM, Catalano R, Locatelli M, et al. $\beta$-Arrestin 2 is required for dopamine receptor type 2 inhibitory effects on AKT phosphorylation and cell proliferation in pituitary tumors. Neuroendocrinology. 2020 Jun 8. Epub ahead of print.

166 Beaulieu JM, Sotnikova TD, Marion S, Lefkowitz RJ, Gainetdinov RR, Caron MG. An Akt/beta-arrestin 2/PP2A signaling complex mediates dopaminergic neurotransmission and behavior. Cell. $2005 \mathrm{Jul}$ 122(2):261-73. 